Cindy van Boven*

\title{
Phonological restrictions on nominal pluralization in Sign Language of the Netherlands: evidence from corpus and elicited data
}

\author{
https://doi.org/10.1515/flin-2021-2039
}

\begin{abstract}
This study focuses on nominal pluralization in Sign Language of the Netherlands (NGT). The aim is to offer a comprehensive description of nominal pluralization processes in the language, based on both corpus data and elicited data, taking into account potential phonological restrictions. The results reveal that NGT nouns can undergo several pluralization processes, the main ones being simple reduplication (i.e., repeating the noun sign at one location) and sideward reduplication (i.e., repeating the noun sign while moving the hand sideward). The choice of pluralization process depends on phonological properties of the base noun: (i) nouns that are body-anchored or involve a complex movement undergo simple reduplication; (ii) nouns articulated at the lateral side of the signing space undergo sideward reduplication; (iii) nouns articulated on the midsagittal plane can undergo both simple and sideward reduplication. Strikingly, the data show considerable variation, and all types of nouns can be zero-marked, that is, plural marking on the noun is not obligatory. The results further suggest that all nouns can undergo at least one type of reduplication. Thus, while phonological properties of the base noun influence the type of reduplication, they do not block reduplication altogether. Plural reduplication in NGT is therefore less constrained than has been reported for other sign languages, where certain noun types cannot undergo reduplication. This shows that reduplication - despite being iconically motivated - is subject to languagespecific grammatical constraints.
\end{abstract}

Keywords: nominal pluralization; phonological allomorphy; reduplication; Sign Language of the Netherlands; sign language typology

*Corresponding author: Cindy van Boven, University of Amsterdam, Spuistraat 134, 1012 VB Amsterdam, The Netherlands, E-mail: c.m.j.vanboven@uva.nl. https://orcid.org/0000-0003$2973-6620$ 


\section{Introduction}

Previous research has shown that sign languages display strong cross-linguistic similarities in their morphological structures. Morphologically complex forms display modality-specific properties since sign languages rarely employ sequential affixation of morphemes; rather, their morphology is largely simultaneous, that is, inflectional and derivational processes often occur stem-internally. Sequential morphological processes do occur, albeit less frequently, and they show less complexity than the simultaneous processes. This division within one language is unique for sign languages (Aronoff et al. 2005).

Given the modality-specific properties of sign language morphology, it is striking that one morphological process is common in both modalities, namely reduplication, i.e., the repetition of (part of) a stem. Interestingly, reduplication is not stem-internal. It has similar functions in spoken and sign languages - for instance, forming the plural of a noun, modifying the verb for aspectual distinctions, or deriving the reciprocal form of the verb. Often - but not always - reduplication is iconic, in that there is a form-meaning correspondence. An example of plural reduplication is given in (1) for Warlpiri, an Australian language (Nash 1980: 130), and in Figure 1 for German Sign Language (DGS) (Pfau and Steinbach 2005; image from Pfau 2016: 216) (for the glossing conventions used for the sign language examples see Appendix A).

(1)

$$
\begin{array}{ll}
\text { kurdu } & \text { kurdu-kurdu } \\
\text { 'child' } & \text { 'children' }
\end{array}
$$

(Warlpiri; Nash 1980: 130)
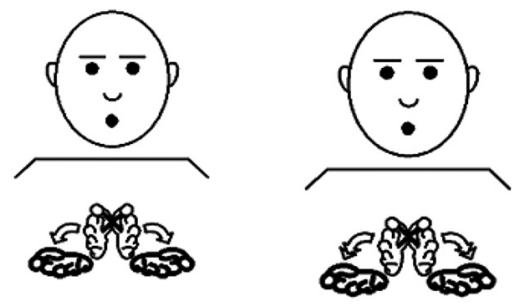

\section{$\mathrm{BOOK}-\mathrm{BOOK}++$}

Figure 1: Reduplication in DGS (Pfau and Steinbach 2005; image from Pfau (2016: 216); @ John Benjamins, reprinted with permission). 
Reduplication is commonly found as a pluralization strategy across sign languages. Yet, previous research suggests that not all nouns can undergo reduplication: phonological features of the base noun have been found to constrain reduplication, and these constraints differ per sign language (Pfau and Steinbach (2005) for DGS; Pizzuto and Corazza (1996) for Italian Sign Language [LIS]; SuttonSpence and Woll (1999) for British Sign Language [BSL]).

The present study focuses on reduplication of nouns as a pluralization strategy in Sign Language of the Netherlands (Nederlandse Gebarentaal, NGT). Some previous studies have addressed pluralization in this language (Harder et al. 2003; Zwitserlood and Nijhof 1999), and yielded interesting results. However, to date, no comprehensive description of nominal pluralization in NGT is available. Moreover, the studies contradict each other on the role of reduplication: while Zwitserlood and Nijhof suggest that reduplication of the noun sign is not a systematic means to form the plural in NGT, Harder et al. find that it actually is. Therefore, this study aims to offer a comprehensive description of pluralization in NGT, based on both corpus data and elicited data, taking into account potential phonological restrictions.

Section 2 provides some background on the phonological structure of signs in general, and on nominal plurals in sign languages specifically. The section concludes with the present study's aims and predictions. Section 3 goes into the methodology used, first providing more details on the corpus data set, next describing the data elicitation procedure, as well as the data analysis. Section 4 provides an overview of results, while Section 5 addresses the variation found, showing how the results complement previous findings on NGT and other sign languages. Finally, Section 6 draws some conclusions.

\section{Nominal plurals in sign languages}

While the pluralization of nouns is often mentioned in textbooks and grammatical sketches of sign languages, to date detailed investigations on nominal plurals are only available for a handful of sign languages. Before reporting findings from these studies in Section 2.2, in Section 2.1, I first introduce basics of the phonological structure of signs that will turn out to be relevant to the discussion of pluralization strategies found across sign languages. Section 2.3 then describes how certain phonological properties of the base noun may affect the choice of pluralization strategy. Section 2.4 addresses previous research on Sign Language of the Netherlands, the focus of this study. Finally, Section 2.5 introduces the main aims and predictions of this study. 


\subsection{Phonological structure of signs}

In sign languages, multiple articulators are available, i.e., the two hands. Thus, signs may be one- or two-handed, and they have phonological structure at the manual level. Sublexical building blocks (sometimes called 'parameters') that have been identified are the handshape (hand configuration), place of articulation, and movement (Sandler 1989; Stokoe 1960; for an overview, see Fenlon et al. 2017). These building blocks can be contrastive: for instance, two signs may differ in terms of their handshape alone. Sign languages being visual languages, there is an increased potential for iconicity, that is, the building blocks of a sign may reflect semantic properties of the referent (e.g., Mandel 1977; van der Kooij 2002). This is clear in Figure 1 above, which illustrates the iconic sign воок in DGS.

It has further been proposed that each of the building blocks can be described in terms of distinctive features, which are organized in feature hierarchies. Various phonological models have been put forward, which differ in feature (under) specification and relationships among features, but details of the models are beyond the scope of this paper (see, e.g., Brentari 1998; Liddell and Johnson 1989; van der Hulst 1993). In the context of the present discussion, only certain movement and location features will be of relevance.

Apart from the manual building blocks, signs are often accompanied by linguistic elements expressed on the body and/or the face, so-called non-manual markers. These non-manual markers may fulfill functions at various grammatical levels (Pfau and Quer 2010). For instance, they have a morphological function when a sign is accompanied by blown cheeks to yield augmentative meaning, or a syntactic function when a headshake accompanies a negated sentence. Relevant to the present discussion is the fact that signs are sometimes accompanied by a mouthing (Bank 2015; Boyes Braem and Sutton-Spence 2001): a (silent) articulation of a (part of a) spoken language word, as in (2), where the NGT signs воок and READ are accompanied by articulations of the Dutch spoken words boek 'book' /buk/ and lees 'read' /le:s/, respectively. Note that while in this case the whole words are pronounced, sometimes only part of the corresponding word in spoken language is articulated.

$$
\begin{aligned}
& \frac{/ \text { buk } /}{\text { [...] }} \frac{\text { Ble:s/ }}{\operatorname{READ}[\ldots]} \\
& \text { '[...] read a book [...]' } \\
& \text { (NGT; CNGT0170; 02:46.080) }
\end{aligned}
$$




\subsection{Plural marking on the noun: manual and non-manual strategies}

Across sign languages, different nominal pluralization strategies have been found, which overlap with those identified in spoken languages (for an overview, see for instance Pfau and Steinbach (2006); Steinbach (2012); also see Section 2.4 for a summary of previous findings on NGT). First, pluralization by means of reduplication has been described for many sign languages (for instance, Pfau and Steinbach (2005, 2006) for DGS; Pizzuto and Corazza (1996) for LIS; Sutton-Spence and Woll (1999) for BSL). Noun reduplication comes in two types: simple and sideward. Under simple reduplication, the movement of the noun is repeated at the same location, while sideward reduplication implies that the repetition is combined with a sideward movement, both illustrated in Figure 2 with signs from DGS: (a) the noun воок undergoes simple reduplication (already illustrated in Figure 1 above, but repeated here as Figure 2a), while (b) the noun CHIL is pluralized by means of sideward reduplication (Pfau and Steinbach 2005; images from Pfau 2016: 216).
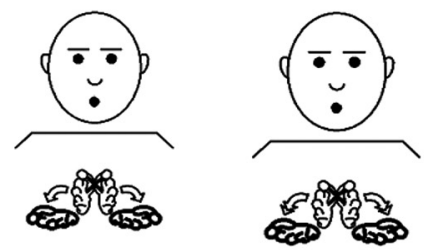

a. $\mathrm{BOOK}-\mathrm{BOOK}++$
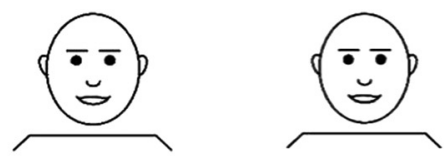

(u)<smiles>C=C=[Mg]</smiles>

Figure 2: Simple (a) and sideward (b) reduplication in DGS (Pfau and Steinbach 2005; images from Pfau (2016: 216); @ John Benjamins, reprinted with permission).

The displacement in sideward reduplication does not add to the meaning; thus, the meaning of the plural form in Figure $2 b$, for instance, is 'children', not '(three) children next to each other'. Moreover, under both types of reduplication, the stem may be repeated more than once - in the DGS examples, we actually observe triplication rather than duplication. Yet, there is variation among signers in the number of repetitions (e.g., Pfau and Steinbach 2005, 2006).

The above processes are sequential in nature. ${ }^{1}$ However, given the availability of two articulators (the two hands), some sign languages display simultaneous

1 A simultaneous pluralization strategy that is not discussed here is numeral incorporation, under which specific nouns (e.g., DAY, WEEK in NGT, or POUND in BSL) take on the handshape of a numeral (see, e.g., Jones 2013; Ktejik 2013; Sutton-Spence and Woll 1999). 
reduplication, where a one-handed noun is articulated with two hands. For instance, in American Sign Language (ASL), one-handed nouns articulated on the face are generally pluralized by repeating the sign alternately with both hands (Wilbur 1987).

Another plural strategy attested in sign languages (as in spoken languages) is zero marking. Some sign languages do not distinguish between the plural and singular form. For instance, Indo-Pakistani Sign Language is reported to usually not distinguish between singular and plural, and plurality thus has to be inferred from the context or is marked by numerals or quantifiers (Zeshan 2000). In other languages, such as DGS, zero marking occurs when there is a numeral or quantifier within the determiner phrase (DP), that is, nominal pluralization is blocked by the presence of a numeral or quantifier (Pfau and Steinbach 2005).

Apart from manual marking, mouthings may also play a role in pluralization. For instance, for Norwegian Sign Language (NSL), Halvorsen et al. (2014), in Quer et al. 2017) describe that a mouthing accompanying a reduplicated noun may be lengthened, as for example the mouthed Norwegian word garn 'skein' /gain/ in (3a). While changes in the mouthing thus may go hand in hand with reduplication, they may also be the sole marker of plurality: a zero-marked noun may be accompanied by a mouthing of the plural Norwegian word as in (3b), where GUTT 'boy' is not reduplicated, but accompanied by the plural form of the Norwegian noun, i.e. gutter 'boys' /gutər/ (Halvorsen et al. 2014, in Quer et al. 2017: 246-247).
a.
/ga:nd
GARN
GARN++
'skein'
'skein(PL)'
(NSL; Halvorsen et al. 2014, in Quer et al. 2017: 246)
b. /gut/
GUTT
/gutər/
GUTT
'boy'
'boys'
(NSL; Halvorsen et al. 2014, in Quer et al. 2017: 247)

\subsection{Phonologically triggered allomorphy}

As described above, several pluralization strategies have been found across sign languages. Often, one sign language has multiple pluralization strategies at its disposal. Two of the phonological building blocks, i.e. place of articulation and movement type, have been shown to influence the choice of pluralization strategy in several sign languages. This phonologically triggered allomorphy is the focus of this section. First, the different phonological noun types that have been found to undergo different pluralization strategies will be introduced. 
Phonological allomorphy was first described for DGS by Pfau and Steinbach (2005, 2006), who distinguish four different phonological noun types and show that different noun types undergo different pluralization strategies - as will become clear, these phonological constraints differ per sign language. While adopting the basic phonological noun types distinguished by Pfau and Steinbach, I also make more fine-grained distinctions in terms of phonological features. An overview of the distinctions made here is provided in Figure 3.

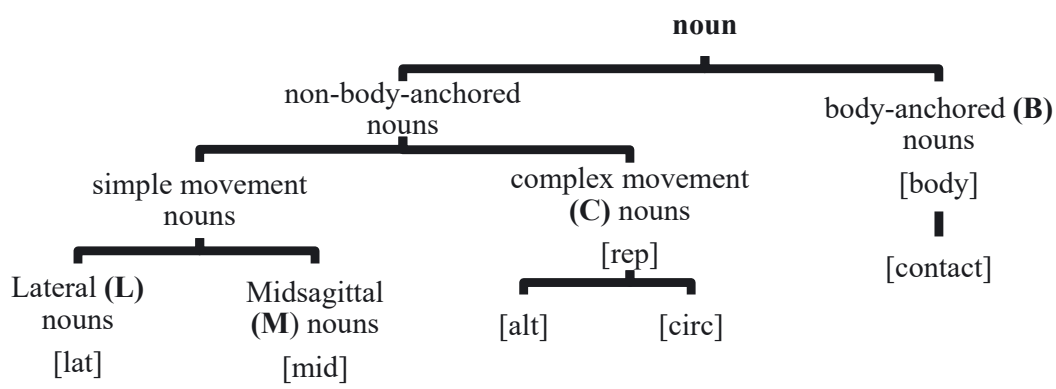

Figure 3: Noun types distinguished in the present study (based on Pfau and Steinbach (2005: 118)).

First, I follow Pfau and Steinbach in making a distinction based on place of articulation, that is between nouns that are body-anchored (B), and those that are not. All nouns that have a feature [body(-anchored)] are subsumed under B-nouns. 'Body-anchored' does not necessarily imply that the articulation of the noun involves contact with the body; rather, it concerns nouns that are not articulated in neutral space, but which have a place of articulation which is clearly related to the body, as the NGT signs in Figure 4. While man does not contact the body (a), MOTHER contacts the

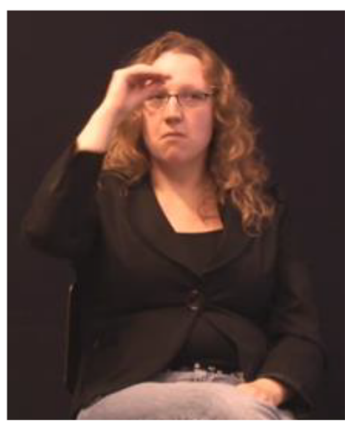

a. MAN

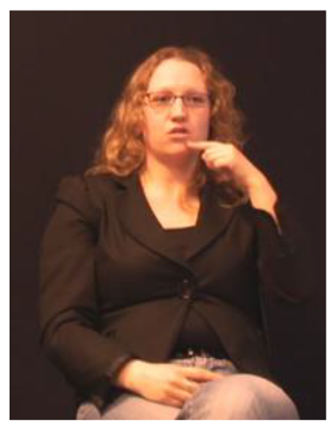

b. MOTHER

Figure 4: Body-anchored (B) nouns in NGT: (a) without body contact [CNGT0124; 00:15.520] and (b) with body contact [CNGT0138; 01:10.760]. 
chin (b). Within the class of B-nouns, I therefore make a distinction between nouns that have a feature [contact], and nouns that are not specified for that feature.

Next, there are nouns that are not body-anchored. For these, I follow Pfau and Steinbach in distinguishing between two types, based on their movement specification: nouns with complex movement and nouns with simple movement. All complex movement (C) nouns have a repeated movement, i.e., a [rep] feature. Additionally, they may have a circular [circ] and/or an alternating [alt] movement. Two examples are provided in Figure 5, where CAR involves a repeated and alternating movement (a), and BICYCLE is repeated, alternating and circular (b).

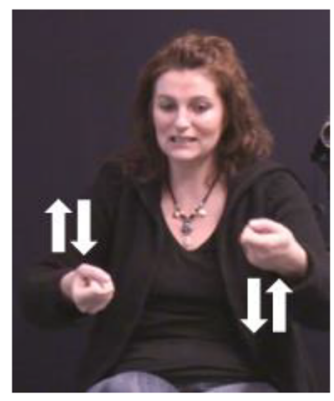

a. CAR

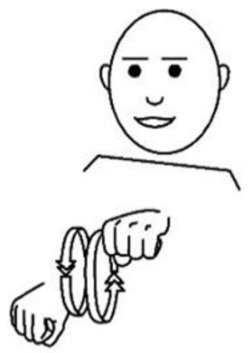

b. BICYCLE

Figure 5: Complex movement (C) nouns in NGT, ${ }^{2}$ involving repeated and alternating (a) [CNGT0171; 04:10.4] or circulating (b) movement (Pfau 2016: 217; @ John Benjamins, reprinted with permission).

On the other hand, simple movement nouns are not specified for repetition in their base form. Like Pfau and Steinbach, I make a further distinction within the group of simple movement nouns by distinguishing midsagittal (M) nouns from lateral (L) nouns, the difference being their place of articulation. While both are articulated in the neutral signing space in front of the signer's body, M-nouns "are specified for a particular relation to the midsagittal plane”, while L-nouns "are signed on the lateral side of the signing space, which, of course, is dependent on the handedness of the signer" (Pfau and Steinbach 2005: 118). Thus, the place of articulation of L-nouns is lateral, i.e., they have a [lat] feature, while M-nouns are midsagittal, i.e. [mid]. Examples of both noun types from DGS were already given in Figure 2, namely the M-noun воок and the L-noun сніLD. In NGT, the signs воок and cHILD have the exact same form as in DGS, and thus NGT вOOK is an M-noun, while NGT CHILD is an L-noun.

2 Note that in Pfau (2016), Figure 5b is actually given as an example from DGS. However, since the noun BICYCLE has the exact same form in NGT as in DGS, I use it as an NGT example here. 
Pfau and Steinbach $(2005,2006)$ show for DGS that the noun type influences the choice of pluralization strategy. First, L-nouns undergo sideward reduplication, as was already illustrated for the L-noun cHILD in Figure $2 b$ above; other pluralization strategies, such as simple reduplication, are ungrammatical for L-nouns in DGS. For M-nouns, on the other hand, Pfau and Steinbach show that sideward reduplication is ungrammatical. Instead, M-nouns are pluralized by means of simple reduplication as already shown for the M-noun воок in Figure 2a above. Finally, both C-nouns and B-nouns do not undergo any type of reduplication and thus are zero-marked: for both noun types, the plural is not formally distinguished from the singular. Note that zero marking is claimed to be ungrammatical for M- and L-nouns in DGS - they necessarily undergo simple or sideward reduplication, respectively.

It turns out that these phonological constraints on pluralization differ per sign language (see e.g. Pizzuto and Corazza (1996) for LIS; Sutton-Spence and Woll (1999) for BSL; Wilbur (1987) for ASL). I will come back to the cross-linguistic differences regarding constraints on reduplication in Section 5.3.

\subsection{Previous studies on NGT: disentangling pluralization and spatial distribution}

We now turn to pluralization in NGT, the language under investigation. Zwitserlood and Nijhof (1999) previously investigated nominal pluralization in this language by eliciting singular and plural forms of several nouns from four native NGT signers. Participants were presented with pictures of singular and plural objects and were instructed to explain what was in the picture. Strikingly, the authors did not find reduplication of the noun itself to be a systematic pluralization process. Instead, they found that plurality was commonly marked by means of localization. When localizing entities in the signing space, signers associate a certain point in space with a specific entity - a strategy that is found to be ubiquitous in sign languages, independent of number marking. Localizing entities in space can be done by means of, for instance, pointing (index) or classifier signs.

I illustrate the localization strategy found by Zwitserlood and Nijhof by means of two examples. First, in their data, the noun was often followed by a contour sign or a classifier, articulated at different locations. These locations indicate the spatial arrangement of the plural objects. In Figure 6a, the noun BICYCLE is followed by a classifier handshape that is localized at several locations next to each other in the signing space, indicating that there are five bicycles in a row (Zwitserlood and Nijhof 1999: 69). Similarly, nouns were sometimes also followed by indexes pointing at different locations, again localizing the plural referents in space. This is illustrated in Figure 6b, where the noun APPLE is followed by five index signs, 
indicating the locations of the apples (Zwitserlood and Nijhof 1999: 70). These processes were not found to be obligatory.

a.
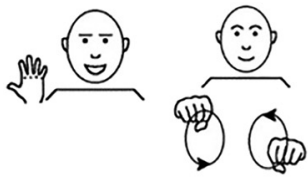

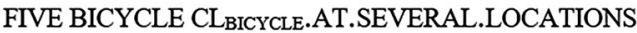

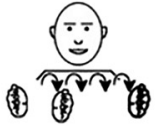

b.

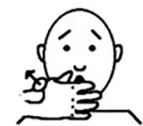

APPLE INDEX $3 a, 3 b, 3 c, 3 d, 3 e$

Figure 6: Pluralization of the NGT noun BICYCLE by means of localizing classifiers (a), the translation is: 'There are five bicycles (in a row).'; and pluralization of the NGT noun APPLE by means of localizing index signs (b), the translation is: 'There are several apples.' (adapted from Zwitserlood and Nijhof (1999: 69-70); ( Inge Zwitserlood, reprinted with permission).

It is not surprising that Zwitserlood and Nijhof found this type of pluralization by means of localization. As the authors note, the elicitation pictures showed objects in a certain spatial arrangement; consequently, signers expressed these spatial arrangements in their signed productions. Thus, the localization of contour signs, classifiers, and index signs actually does not express a 'pure' plural but adds spatial meaning to the signers' productions. Moreover, the authors did not take into account potential phonological restrictions. Still, they also found cases of simple reduplication of the noun. Two explanations are offered: (i) the signer repeated the noun sign while thinking about how to tell what was on the picture, or (ii) the number of syllables in the mouthing of the Dutch plural word influenced the number of movements in the sign - indeed, previous studies have described a tendency for hand and mouth movement to be synchronized (Boyes Braem 2001; Sandler 1999).

However, the possibility that nominal reduplication plays a role in NGT pluralization should not be excluded since another study on the topic by Harder et al. (2003) actually found reduplication of the noun sign. Their data set consisted of material for students of NGT at the Nederlands Gebarencentrum (Dutch Sign Centre). While Harder et al., too, describe localization of classifiers and index signs to be one strategy, nominal reduplication is also mentioned. They even identify some phonological restrictions: reduplication was found to be ungrammatical for signs with a complex movement in their base form as well as for signs articulated on or above the crown. Also, while the plural of body-anchored signs was formed by simple reduplication, the plural of signs articulated in neutral space was usually formed by sideward reduplication. Moreover, they found that one-handed base signs were sometimes articulated with two hands in order to indicate plurality. Unlike in DGS, Harder et al. also describe that reduplication is not blocked by numerals/quantifiers in NGT. Notably, these findings differ from what has been 
reported by Zwitserlood and Nijhof (1999). Harder et al. offer the possible explanation that more different signs were included in the data set, and that phonological properties were taken into account in this study, but not in the study by Zwitserlood and Nijhof.

While these two studies certainly paint a first picture of the pluralization strategies in NGT, no comprehensive and systematic description of the 'pure' plural form of NGT nouns, taking into account the different noun types, has been offered so far. The studies contradict each other on the role of reduplication, and it remains unclear what the plural form looks like when it is completely disentangled from localizing plural referents in space.

\subsection{The present study}

The aim of the present study is to systematically describe the nominal pluralization strategies in NGT, completely disentangling pluralization from localization. Thus, it focuses on those strategies which convey plural meaning without a specific spatial arrangement. It also describes the potential phonological restrictions on these pluralization strategies, based on the phonological noun types introduced in Section 2.3. Finally, it compares the findings to other sign languages.

Based on the previous literature, several factors are investigated. The first concerns the relation between noun type and pluralization strategy. Given that reduplication is a common pluralization strategy in sign languages and because it was found for NGT by Harder et al. (2003), reduplication is expected to be one of the main pluralization strategies. Moreover, reduplication is expected to be constrained by phonological properties of the base noun. Following Harder et al. (2003), B-nouns are expected to undergo simple reduplication, while M-nouns may undergo sideward reduplication. C-nouns are expected to be zeromarked. For L-nouns, no predictions can be formulated based on Harder et al. (2003) - possibly, they undergo sideward reduplication as they do in DGS.

Second, this study also investigates the relation between the pluralization strategy and presence of numerals/quantifiers. In DGS, numerals/quantifiers were found to block reduplication (Pfau and Steinbach 2005, 2006), while Harder et al. (2003) describe that this is not the case in NGT. Finally, the number of repetitions in reduplication is looked into. It is expected that there is individual variation as Pfau and Steinbach $(2005,2006)$ also found for DGS. Possibly, there is a relation between mouth movement and number of repetitions as suggested by Zwitserlood and Nijhof (1999) for NGT. 


\section{Methodology}

This study combines two methodologies: corpus analysis and data elicitation. The starting point is a corpus search in the Corpus NGT (Crasborn et al. 2008; Crasborn and Zwitserlood 2008), which should provide us with a first idea of what pluralization looks like in this language, and which potential restrictions can be identified. However, a well-known caveat in using corpus data is that there is no guarantee that these searches will yield the specific noun types that are required for generalizations. Therefore, the corpus data are supplemented with data elicitation in order to make sure that all relevant noun types are included in the analysis.

\subsection{Corpus data collection}

The Corpus NGT consists of recordings of 92 deaf native NGT signers (age 17-84 years) and contains over $70 \mathrm{~h}$ of video data. Participants were asked to perform several tasks, resulting in both monologues and dialogues. For instance, signers were asked to discuss issues related to Deafness, to retell video clips (i.e. narratives), and to tell stories about past experiences. Moreover, participants also spontaneously talked about topics of their choice; the data are thus partly elicited, and partly (semi-)spontaneous. ${ }^{3}$ Part of these video data has been transcribed using the annotation tool ELAN (Crasborn and Sloetjes 2008); currently, there are 199,293 annotations, ${ }^{4}$ on several tiers. Three tiers are of importance here. First, annotations on the Gloss tiers show the Dutch glosses of the NGT signs; separate tiers are created for the dominant and non-dominant hand. Moreover, there are annotations on the Translation tier, which show translated sentences in Dutch, and the Mouth tier, on which mouth actions are annotated (Crasborn et al. 2015).

The annotated part of the corpus was searched for plural nouns. According to the Corpus NGT Annotation Conventions, "although many NGT signs do not have a plural form, other signs do. These forms [...] are annotated with the gloss for the singular form with an added '.PL' (and not with the plural form of the Dutch gloss)" (Crasborn et al. 2015: 15). I therefore searched for '.pl' on the Gloss tier to find nouns that are overtly marked for plurality. In total, this yielded 284 search

3 For more information on the data elicitation, see https://www.ru.nl/corpusngtuk/ methodology/data_collection/.

4 See the Release Notes for Release 3 of the Corpus NGT Annotation Conventions: https://www.ru. $\mathrm{nl} /$ corpusngtuk/methodology/annotation/. 
hits. Note that two-handed nouns are glossed for .PL twice, namely on the Gloss tier for the dominant hand, and on the Gloss tier for the non-dominant hand. After excluding these double appearances, 221 tokens remained. Subsequently, four tokens were excluded: one because the noun actually referred to a singular referent, one because the video file did not work, and two because the signs were not nouns, but rather a point to the hand and the name of a city. This left 217 tokens for analysis.

However, it was suspected - based on previous research - that certain signs cannot undergo plural reduplication. I also searched - in order to find out whether specific phonological properties could be held responsible for this - for signs that appear in a 'plural context' but are not glossed for .PL, indicating that it is likely that they are not overtly marked for plurality. For this, I searched on the Translation tier for the plural of 12 frequent Dutch nouns, which were taken from a list of the 5,000 most frequent words in the Corpus Gesproken Nederlands ('Corpus Spoken Dutch'; Dutch Language Institute 2014). From this list, the most frequent nouns were selected that were not yet included in the .PL annotations (i.e. huizen 'houses', dagen 'days', weken 'weeks', scholen 'schools', vrouwen 'women', mannen 'men', boeken 'books', moeders 'mothers', vaders 'fathers', problemen 'problems', treinen 'trains', and cafés 'cafés'). It is important to include these nouns since they receive a plural interpretation (and thus translation), even though they are not morphologically marked for plurality - at least according to their glosses. Searching for these nouns yielded 114 search hits. After excluding tokens that involved spatial distribution and tokens in which the NGT noun actually referred to a singular entity, 80 tokens remained for analysis. Thus, in total, 297 plural noun tokens (22 types) from the corpus were analyzed.

\subsection{Data elicitation}

\subsubsection{Participants}

In addition to the corpus data, data were elicited from five deaf native NGT signers (one male, four female, age range 25-62, mean age 38.4) from varying sign language regions in the Netherlands. ${ }^{5}$ Three participants come from a hearing family, while the other two participants have deaf family members. All participants signed

5 There is regional lexical variation in NGT between the north, the south, and the west of the Netherlands (Schermer 2004), which should be kept in mind since our participants identified themselves with various regions. 
informed-consent forms, allowing me to use the data gathered. However, two of them did not grant permission to have their faces shown on figures. In the following, participants will be referred to as p01-p05.

\subsubsection{Stimuli}

For the purpose of this study, i.e. eliciting plural nouns without localization, a gap-filling task was designed: participants were presented with signed (carrier) sentences in which the plural noun was omitted and replaced by a question mark sign, as shown in Figure 7. Participants were asked to repeat the sentence and fill in the gap, based on a picture that shows the targeted plural noun. The picture was shown during the entire carrier sentence. Crucially, spatial configuration is not relevant in the signed contexts, such that only plurality would be expressed by the participants. Participants were explicitly instructed in NGT to only fill in the gap without changing the sentence, such that plurality would indeed be marked on the noun and not on, for instance, the verb. A more elaborate overview of the task and its advantages and disadvantages is provided in van Boven (2020).
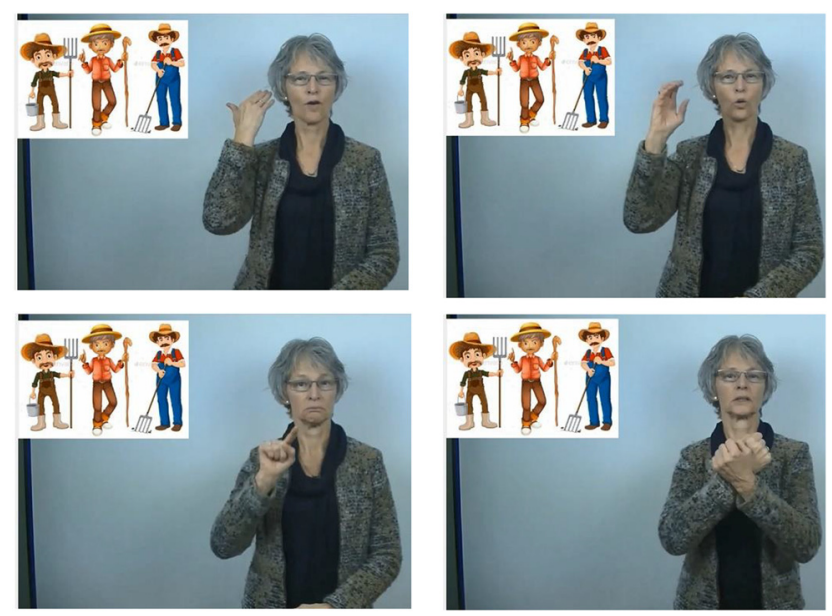

LAST OCTOBER QUESTION.MARK STRIKE

Figure 7: Elicitation clip from the gap-filling task (targeted answer: LAST OCTOBER, FARMER(++) STRIKE 'Last October, the farmers were on strike'). ${ }^{6}$

6 Picture stimulus 'farmers' from https://www.canstockphoto.com/farmers-22036428.html; (C) Can Stock Photo/colematt. 
The task aimed at eliciting eight noun (sub)types, following the phonological distinctions discussed in Section 2.3, and shown in Figure 3. Plural nouns were targeted for each (sub)type. ${ }^{7}$ An overview of the targeted nouns is given in Table 1.

Table 1: Targeted nouns in the gap-filling task, by noun type $(N=21)$.

\begin{tabular}{|c|c|c|}
\hline B-nouns & $\begin{array}{l}\text { [body], [contact] } \\
\text { [body] }\end{array}$ & $\begin{array}{l}\text { FARMER, HUMAN, LAMP, SHOP, HOTEL } \\
\text { GLASSES, }{ }^{8} \text { WOMAN, MAN, MOVIE }\end{array}$ \\
\hline L-nouns & [lat] & CHILD, DOLL, WINE-BOTLE \\
\hline M-nouns & [mid] & BOOK, CHAIR, TROUSERS \\
\hline C-nouns & $\begin{array}{l}\text { [rep] } \\
\text { [rep], [circ] } \\
\text { [rep], [alt] } \\
\text { [rep], [circ], [alt] }\end{array}$ & $\begin{array}{l}\text { PILLOW, BABY, MOUSE } \\
\text { TRAIN } \\
\text { CAR } \\
\text { BICYCLE }\end{array}$ \\
\hline
\end{tabular}

All 21 nouns were targeted twice: once in a sentence without a numeral/ quantifier, and once preceded by a numeral/quantifier. ${ }^{9}$ This resulted in a total of 42 carrier sentences for plural nouns.

Moreover, 11 sentences which elicit singular nouns were added. The function of these was twofold: first, they ensured that participants did not simply reduplicate all signs because they realized that the task is targeting plurals. Second, they elicited the singular forms of those nouns that, according to the NGT dictionary, have an inherent repetition in their citation form, as well as of nouns that were suspected to involve an inherent repetition for at least some signers, ${ }^{10}$ such that the number of repetitions in singulars and plurals could be compared within signers.

7 The nouns were categorized based on their citation form in the NGT dictionary (https://www. gebarencentrum.nl/Gebarenwoordenboek). There may be variation in how participants actually articulate the nouns, leading to a different categorization - see Section 3.3 for further discussion. Moreover, for some nouns, I suspected that they contain an inherent repetition for some signers but not for others - for these I also elicited the base form, see below.

8 Note that the English glosses TROUSERS and GLASSES are underlyingly plural, but the same is not true for the corresponding Dutch words/glosses broek and bril, or the NGT signs.

9 The task contains the following numerals and quantifiers: TWO, THREE, FOUR, FIVE, THREE OR FOUR, TEN; (MANY) DIFFERENT, SEVERAL, FEW, MOST, MANY.

10 Consequently, there are eleven sentences which elicit singular forms with an inherent repetition, while only six C-nouns are included in Table 1. The reason is that some B-nouns also involve inherent repetition, e.g., Movie. I also suspected that some nouns I initially categorized as simple movement nouns, may sometimes also involve an inherent repetition in their citation form, e.g., DoLl. However, as the results for the singular carrier sentences showed that DoLL can actually be 
The 53 elicitation clips were presented by a deaf native signer in a semirandomized order, the same one for all participants. Participants never saw more than four consecutive clips eliciting plural nouns without a clip eliciting a singular noun in between, never more than two carrier sentences with a numeral/quantifier in a row, never the same target noun twice in a row, and never more than two nouns of the same type in a row.

\subsubsection{Pilot study}

Before conducting the gap-filling task, it was piloted with one native signer - the results of this signer are not taken into consideration below. The pilot only served to make sure the task works and indeed elicits plural nouns without localization. To this end, I also discussed the task and possible responses with this native signer after she had finished the test, and she offered her advice on how the test could be improved.

The pilot study showed that, indeed, the carrier sentences elicit plurals without spatial distribution - the participant signed only the 'pure' plural forms. Nevertheless, five elicitation clips were changed for the final version of the task. First, one elicitation clip elicited the singular rather than the plural noun (i.e. for the B-noun LAMP), and therefore a different carrier sentence - which more likely would elicit a plural - was recorded. Second, the two sentences that were meant to elicit the L-noun PERSON elicited HUMAN instead (a B-noun that was already elicited by other sentences). After consulting another deaf native signer, it was clear that eliciting PERSON and not HUMAN would be rather difficult, if not impossible. Therefore, the two sentences meant to elicit PERSON were replaced by two sentences that aimed at eliciting wINE-BOTTLE, another L-noun. Finally, one of the elicitation clips that was meant to elicit the plural of the M-noun воок elicited the singular instead. Apparently, the picture did not clearly indicate that multiple books were aimed at, and therefore it was replaced by a clearer picture. For consistency, the picture for the other clip eliciting the plural of воок was also replaced. ${ }^{11}$

analyzed as an L-noun - as I initially categorized it - rather than a C-noun, I included it as an L-noun in Table 1.

11 Note that although, at this point, it was unclear what the plural form would look like exactly, from the mouthings, the context, and discussions following the test, it became clear in which cases the participant meant the singular rather than the plural form. This also became clear from a comparison to the sentences with quantifiers, where the signer did sign plural forms of LAMP and воок because both signs were reduplicated. 


\subsubsection{Procedure}

After the pilot, five other participants participated in the actual task. They first answered a background questionnaire (on their age, sex, sign region, the hearing status of their family members, and the languages they know). Then they were presented with a clip that showed the instructions for the task in NGT, signed by a native signer. Participants were told that the researchers are interested in different nouns, signed in specific contexts. It was explained that signers will see sentences with one noun being omitted, and that the missing sign is shown to them on a picture. They were further asked to exactly repeat the sentence, only replacing the question mark by an actual sign, based on the picture. Next participants were shown an example sentence and the relevant answer. The example elicited a singular noun so as not to influence participants' plural marking strategies. Moreover, the target noun in this carrier sentence (BREAD) was not used in the actual task.

The stimuli were presented in one long video on a computer screen in front of the participant. After each elicitation clip, participants paused the video before responding and pressed 'Play' again after responding, such that there was no time pressure. Four participants were tested in a recording studio, with one researcher present, whom they could ask questions if necessary. One participant did the test at home without a researcher present but with clear instructions in NGT regarding the procedure. Since she went through the test in the same manner as the other participants, her results are included below. In total, 189 plurals nouns were elicited.

\subsection{Analysis of both data sets}

Both data sets were annotated in ELAN (Crasborn and Sloetjes 2008), and statistical analyses were conducted using $\mathrm{R}$ (R Development Core Team 2008). This section first goes into the data annotation, and then introduces the statistical analyses.

\subsubsection{Data annotation}

For both data sets, only nouns referring to plural referents without spatial configuration were included in the analysis - this was decided mainly based on context. For the annotations, several tiers were created (see Figure 8). 


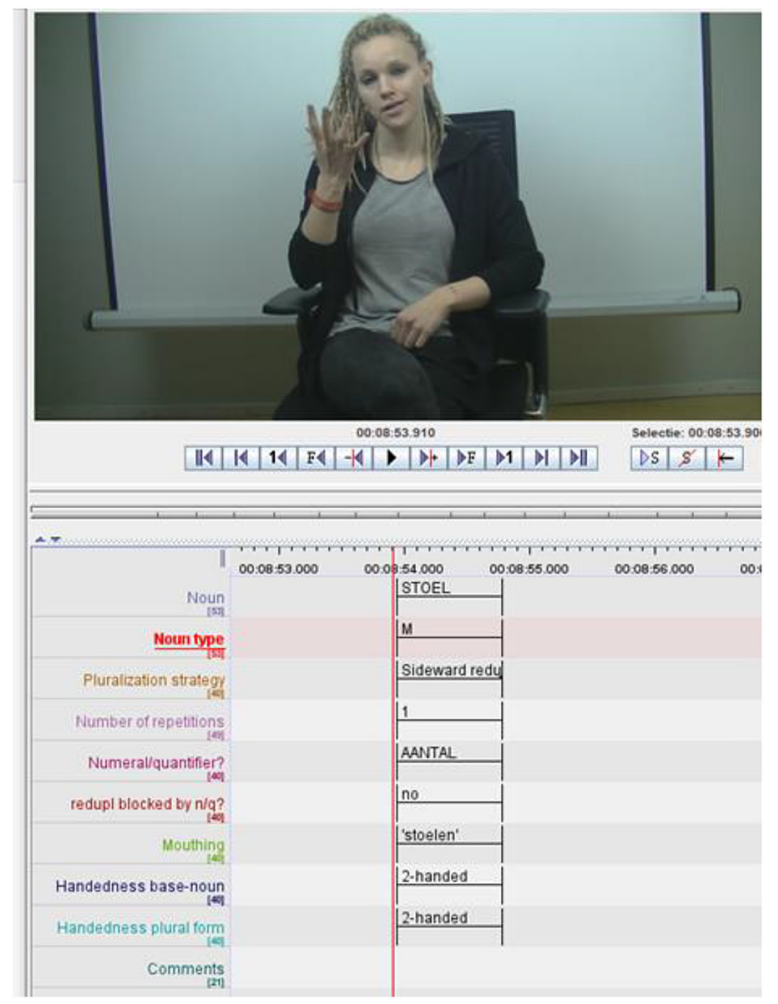

Figure 8: Screenshot from ELAN (Crasborn and Sloetjes 2008), showing the tiers and annotations created for analysis of plural nouns in both data sets.

Figure 8 shows that the plural nouns were annotated for the following characteristics:

(i) phonological properties of the base noun. The data were categorized into noun typesbased on the phonological properties discussed in Section 2.3. Nouns were categorized based on how they were actually articulated - for this reason, one and the same noun can be categorized differently for different signers. For instance, in the data elicitation, some participants made body contact while signing GLASSES, while others did not - as a consequence, this noun was sometimes annotated as B-noun with [contact], and sometimes as B-noun without [contact]. Related to this, even though the elicitation task aimed at eliciting all different noun types, sometimes the clips elicited noun types that were not the target. This has several reasons: (i) some clips elicited a noun that was not the target, and therefore of a different type (e.g. FRIEND instead of HUMAN, where FRIEND was still included in the analysis even though it 
has phonological properties different from the target); (ii) some clips elicited a different variant of the target noun, which belongs to a different type (e.g. for HотеL, there was a B-noun and an M-noun variant); and (iii) in some cases, participants did not repeat the sentence exactly but adapted the elicitation contexts such that a singular rather than a plural noun was articulated.

(ii) pluralization strategy. In the analysis, three possible pluralization strategies were anticipated. First, I annotated 'simple reduplication' when the movement of produced nouns is repeated in comparison to the base noun, which, here, is taken to be the citation form of the respective noun. ${ }^{12}$ However, for nouns with inherent repetition (C-nouns and some B-nouns), there may be individual variation in the number of repetitions in the base noun (as Zwitserlood and Nijhof (1999) also found). Therefore, I compared the elicited plural forms of these nouns to the elicited singular forms; these were within-participant comparisons. Hence, if for instance, a participant articulated the singular C-noun BICYCLE with two circular movements, the same noun in the plural context was analyzed as reduplicated if it involved more than two circular movements (i.e. three or more). Second, 'sideward reduplication' was annotated when the noun was not only repeated but when a sideward movement was also involved. Third, I annotated 'zero marking' when the referent of the noun clearly was a plural entity (based on context), yet no manual marking on the noun could be identified. Of course, it is possible that NGT displays additional pluralization strategies, and thus any other formal adaptation of the noun that possibly indicates plurality was also annotated (such as adding the non-dominant hand, i.e. simultaneous reduplication). Finally, it should be noted that during data elicitation participants sometimes articulated the same noun twice within one sentence; in those cases, only one instance was included in the data analysis. If only one of the two instances was pluralized while the other was not, the pluralized noun was included.

(iii) number of repetitions. If the noun was annotated for (simple or sideward) reduplication, I counted how often the base noun was repeated. For elicited nouns with inherent repetition, this, again, involved within-participant comparison to the singular forms. Thus, if a participant articulated the singular C-noun BICYcLE with two circular movements, for example, one repetition was counted if the entire noun was repeated, that is, in this case if four circular movements were articulated. In some cases, the reduplicated C-noun was articulated with more movement repetitions than the singular form, yet not twice as many. In this particular example, if the plural form of BICYCLE involves

12 Based on the NGT dictionary: https://www.gebarencentrum.nl/Gebarenwoordenboek. 
three circular movements, this was annotated as 'less than one repetition' since it does not involve a complete repetition of the entire base noun.

(iv) presence of a numeral and/or quantifier. It was analyzed whether the plural noun was accompanied by a numeral and/or a quantifier. This was done not only for the corpus data, but also for the elicited data since participants sometimes omitted numerals/quantifiers that were present in the elicitation sentences but also sometimes added numerals/quantifiers when the elicitation context did not contain one. For the corpus data, whenever a numeral/ quantifier was present, it was only annotated which numeral/quantifier this was. The elicited sentences containing a numeral/quantifier, however, were also compared to the sentences without a numeral/quantifier but with the same plural noun (because all plural nouns were elicited in both contexts). This provided insight into whether or not the numeral/quantifier blocked pluralization: if the noun was pluralized by the same participant in the sentence without numeral/quantifier but not in the sentence with numeral/ quantifier, then it was annotated that pluralization was blocked.

(v) mouthings. Another factor of interest was potential non-manual marking of plurals, specifically mouthings, and their relation with number of repetitions. For both data sets, I annotated which Dutch word (or part of word) was mouthed. If there was no mouthing or if the mouthing was not clearly visible, this was also annotated. A native signer checked a representative sample of these annotations. I showed her 16 signs from the data set (eight from the corpus and eight from the elicited data), and asked her to write down the mouthings accompanying these signs. For 13 of those, she noted the same mouthing as I did (81.2\%). The agreement between raters was measured using the irr package (Gamer et al. 2019). The agreement was substantial (Cohen's Kappa $=0.76)$ and greater than would be expected by chance $(z=5.69$, $p<0.001)$. Moreover, I also showed her some nouns where the mouthing was deemed unclear. For some of those, the native signer could discern a mouthing, while for others the mouthing was not clear to her either.

Note that 103 of the nouns extracted from the corpus (i.e. 34.7\%) were already annotated for mouthings (on the Mouth tier); in those cases, the mouthings already annotated were adopted, and a native signer was not asked to check them (since the corpus annotators are native or near-native).

(vi) other factors. Some additional tiers were created. First, it was annotated whether the base noun is one- or two-handed, and whether the plural form is one- or twohanded. Moreover, on a Comments tier, I noted anything else that might be relevant in the context of pluralization - most notably, for the elicited data, whenever the pluralization was not (only) marked on the noun but on another element, this was annotated (a complete list of annotation values per tier is given in Appendix B). 


\subsubsection{Statistical analyses}

To investigate the relevant factors introduced in Section 2.5, three statistical analyses were conducted. First, I analyzed statistically whether certain phonological properties block reduplication in NGT - specifically [body] and [rep] as was found for other sign languages. Second, I analyzed statistically whether numerals and quantifiers block reduplication in NGT. For both of these analyses, I fitted generalized linear mixedeffects models using the lme4 package (Bates et al. 2015). For each analysis, I built a model with zero marking as the dependent variable, which was converted into a binomial factor with two levels: 'yes' or 'no', since it was only relevant whether all types of reduplication were blocked for B- and C-nouns and for sentences with a numeral/ quantifier. For the first model, noun type and data type were included as fixed effects. For the second model, presence of numeral/quantifier and data type were included as fixed effects. Data type was included to check whether there were differences between the corpus and the elicited data. With the aim to fit a maximal model justified by the design (Barr et al. 2013), a random intercept for subject was also included in both models as well as a by-subject random slope for noun type in the first model and for presence of numeral/quantifier in the second.

For the first model, I used orthogonal sum-to-zero contrast coding for the noun-type variable. I set the following comparisons: a) B-, L-, and M-nouns against C-nouns (contrast coded as $-0.25,-0.25,-0.25,+0.75$, respectively); b) L- and M-nouns against B- and C-nouns (contrast coded as $-0.25,-0.25,+0.25,+0.25$, respectively); and c) $\mathrm{C}$-, L-, and M-nouns against B-nouns (contrast coded as $-0.25,-0.25,-0.25,+0.75$, respectively). I also used orthogonal sum-to-zero contrast coding for the data type variable. Corpus data was coded as -0.5 and elicited data as +0.5 .

For the second model, I used orthogonal sum-to-zero contrast coding for the numeral/quantifier variable. No numeral/quantifier present was coded as -0.5 and numeral/quantifier present was coded as +0.5. I also used orthogonal sum-tozero contrast coding for the data type variable. Corpus data was coded as -0.5 and elicited data as +0.5 .

To avoid problems of model convergence in both models, the number of possible iterations of the BOBYQA optimizer was increased up to 1.000.000.

Finally, it was analyzed statistically whether there is a correlation between the number of syllables in the mouthing and the number of repetitions in the noun. First, the data were trimmed, i.e. I excluded (i) nouns for which the number of repetitions was unclear and (ii) unclear mouthings. I then applied a Pearson correlation test to the trimmed data to test the correlation between number of repetitions and the number of syllables in the accompanying mouthing. 


\section{Results}

\subsection{Data overview}

In total, 297 plural nouns were extracted from the Corpus NGT, and 189 plural nouns were elicited. For an overview of the nouns in both data sets, see Table $2 .^{13}$ (Appendix $\mathrm{C}$ shows the specific nouns that are included under each type.)

Table 2: Plural nouns in the corpus and elicited data sets (tokens).

\begin{tabular}{lrrr}
\hline & Corpus & Elicited & Total \\
\hline B-nouns & 88 & 97 & 185 \\
L-nouns & 194 & 30 & 224 \\
M-nouns & 11 & 26 & 37 \\
C-nouns & 4 & 36 & 40 \\
Total & 297 & 189 & 486 \\
\hline
\end{tabular}

As mentioned in Section 3.3, some carrier sentences elicited nouns that were not targeted. These nouns were included in the analysis, and therefore, the elicited data are not equally distributed over the different noun types. Furthermore, as also mentioned, sometimes carrier sentences did not elicit plural nous as planned (but rather singulars), and therefore the total of elicited plurals does not add up to the expected 210 nouns (i.e. 42 plural elicitation contexts for five signers). The data are also not equally distributed over the different noun types for the corpus data set. Notably, C- and M-nouns are under-represented. Strikingly, C-nouns occur much less frequently in the spontaneous corpus data than in the elicited data. ${ }^{14}$

13 For the B-nouns, 53 corpus nouns and 60 elicited nouns are specified for [contact], while the other 35 corpus nouns and 37 elicited nouns are not. For the C-nouns, one corpus noun and ten elicited nouns are specified for [alt], one corpus noun and ten elicited nouns are specified for [circ], and no corpus nouns but seven elicited nouns are both [circ] and [alt]. The other two corpus C-nouns and nine elicited C-nouns involved neither [circ] nor [alt], i.e. they only contain a repeated movement.

14 A reviewer pointed out that the rarity of C-nouns in the naturalistic data - and by extension, in the language - might be associated with different patterns of pluralization. This was not systematically analyzed here, but as Table 4 shows, C-nouns at least undergo simple reduplication, just as other noun types. It is striking, however, that a large percentage of C-nouns is zero-marked. Possibly, this is related to the fact that C-nouns occur less frequently than any other noun type in naturalistic language data. 
Further, while all L-nouns in the data are one-handed signs, the analyzed $\mathrm{M}$ and C-nouns are all two-handed. ${ }^{15}$ The class of B-nouns includes one- $(N=134$ tokens) and two-handed ( $N=51$ tokens) signs. Moreover, while the classes of Band L-nouns include both animate and inanimate nouns, all M-nouns refer to inanimate entities, and C-nouns mostly refer to inanimate entities - BABY is the only exception (see Appendix C).

The following sections discuss the relation between pluralization strategies and the different noun types (4.2), the relation between reduplication and the presence of a numeral or quantifier (4.3), as well as the number of repetitions in the nouns and its relation to mouth movement (4.4). The section concludes with a discussion of plural marking on elements other than the noun (4.5).

\subsection{Noun types and pluralization strategies}

Table 3 shows the distribution of pluralization strategies found in both data sets, irrespective of noun type. Table 4 shows the percentages of the pluralization strategies for the specific noun types in the corpus and elicited data.

Table 3: Distribution of pluralization strategies in the corpus and elicited data sets.

\begin{tabular}{lrrr}
\hline & Total & Corpus NGT & Elicited \\
\hline Zero marking & 148 & 76 & 72 \\
Simple reduplication & 133 & 62 & 71 \\
Sideward reduplication & 197 & 153 & 44 \\
Others & 8 & 6 & 2 \\
Total & & 297 & 189 \\
\hline
\end{tabular}

Table 4: Pluralization strategies per noun type in the corpus and elicited data (percentage); boldface indicates most frequent strategies.

\begin{tabular}{lrrrrr}
\hline Noun type & $\boldsymbol{N}$ (total) & Zero marking & Simple reduplication & Sideward reduplication & Others \\
\hline B-noun & 185 & $\mathbf{7 4}(\mathbf{4 0 . 2 \% )}$ & $\mathbf{1 0 3 ( 5 5 . 7 \% )}$ & $6(3.2 \%)$ & $2(1.1 \%)$ \\
L-noun & 224 & $\mathbf{3 5 ( 1 5 . 6 \% )}$ & $4(1.8 \%)$ & $\mathbf{1 8 1}(\mathbf{8 0 . 8 \% )}$ & $4(1.8 \%)$ \\
M-noun & 37 & $\mathbf{1 6}(\mathbf{4 3 . 2 \% )}$ & $\mathbf{1 1}(\mathbf{2 9 . 7 \% )}$ & $\mathbf{8}(\mathbf{2 1 . 6 \% )}$ & $2(5.4 \%)$ \\
C-noun & 40 & $\mathbf{2 3 ( 5 7 . 5 \% )}$ & $\mathbf{1 5}(\mathbf{3 7 . 5 \% )}$ & $2(5 \%)$ & $0(0 \%)$ \\
\hline
\end{tabular}

15 While one-handed C-nouns exist in NGT (e.g., sIREN), but happened not to be included in the data set, I suspect that there are no one-handed M-nouns in NGT. One-handed nouns articulated on the midsagittal plane are also body-anchored (e.g., APPLE), and are therefore specified as B-nouns in the present classification. 
The descriptive analyses show that zero marking occurs with all distinguished noun types, i.e. plural marking is clearly not obligatory in NGT. At the same time, Table 4 also makes clear that each noun type can undergo at least one type of reduplication - although a larger proportion of C-nouns is zero-marked compared to the other noun types (see also Footnote 14).

As described in Section 3.3.2, it was analyzed statistically whether C- and B-nouns undergo zero marking more often than M- and L-nouns. Because the fixedeffect model matrix was rank deficient for the comparison of B-nouns against M-, L-, and C-nouns (i.e. there was not enough data), I only report the C-nouns against B-, L, and M-nouns and the B- and C-nouns against M- and L-nouns comparisons. No significant effect of data type $(p=0.54)$ nor a significant difference between C-nouns and the other noun types ( $p=0.11$ ) were found. Yet, participants were ten times more likely to use zero marking with B- and C-nouns than with L- and M-nouns (odds ratio $=10.24, p<0.001, z=4.23$, 95 percent confidence interval from 3.49 to 30.06) (an overview of all statistical data for the fixed effects is provided in Appendix D).

Thus, strikingly, I did not find a significant difference with respect to zero marking between $\mathrm{C}$-nouns and the other noun types, but when combining the B-nouns with the $\mathrm{C}$-nouns in the comparison, rather than with the $\mathrm{M}$ - and L-nouns, there was a significant effect. This suggests that the significant difference results from adding the B-nouns to the C-nouns; however, I cannot check whether B-nouns alone also are more likely to undergo zero marking since that comparison was dropped. For now, the statistical analysis suggests that B- and C-nouns are more likely to be zero-marked by the participants than M- and L-nouns.

Nevertheless, it cannot be concluded that [rep] and [body] block reduplication altogether: after all, 37.5\% of C-nouns and 55.7\% of B-nouns undergo simple reduplication; sideward reduplication, however, is rare for these noun types. Indeed, when plural marking occurs, there are some patterns related to the phonological noun types. I only go into the most frequent patterns here, marked in boldface in Table 4. These patterns are not categorical, and the variation found will be discussed in Section 5.2.

B-nouns (with and without contact), C-nouns (all movement types), and M-nouns can undergo simple reduplication as exemplified ${ }^{16}$ in Figure $9 a-c$. In these figures, the plural is formed by repeating the movement of the noun at the same location.

16 For all examples from the corpus NGT, the Corpus NGT file number + begin time (m:s.ms) is given between square brackets. For the glossed examples from the elicited data, participant number (p01-p05) is provided, while for screenshots from the elicited data no participant code is provided (in order to ensure that participant code cannot be linked to individual participants). 
a.
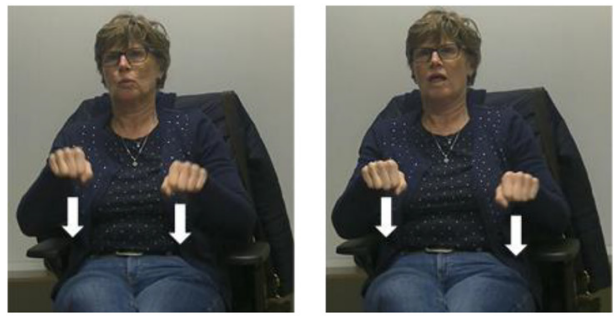

CHAIR+

b.
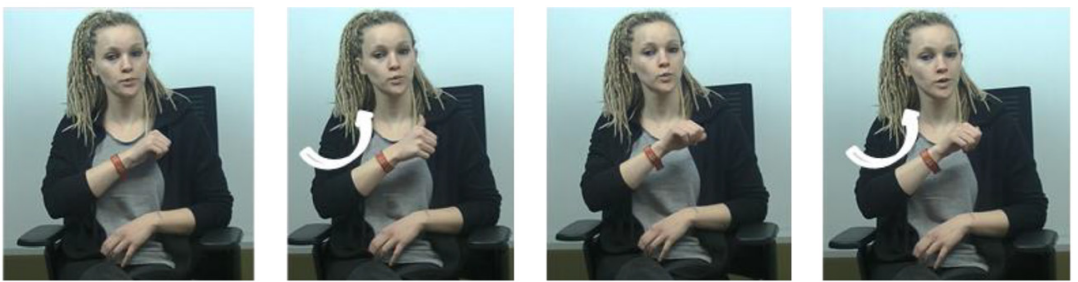

FARMER+
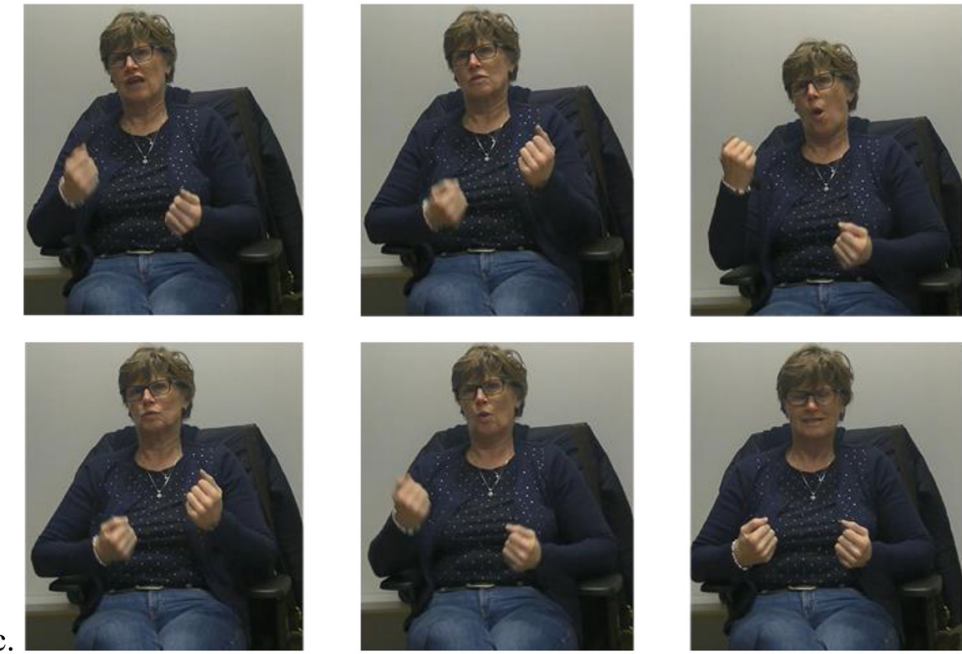

\section{$\mathrm{CAR}+++$}

Figure 9: Pluralization by simple reduplication: (a) of M-noun CHAIR (a downward movement is made twice at the same location); (b) of B-noun FARMER (thumb makes contact with the body twice while lower arm is rotated outward); (c) of C-noun CAR (six alternating movements; the singular version by the same participant contains two alternating movements). 
Strikingly, the elicited data suggest that M-nouns actually cannot only undergo simple but also sideward reduplication - this is illustrated in Figure 10, where the noun CHAIR is not only repeated, but also displaced.
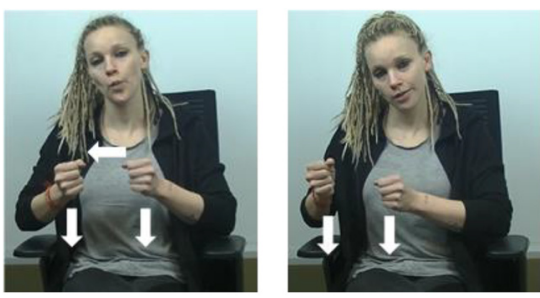

CHAIR $>+$
Figure 10: Pluralization by sideward reduplication of M-noun CHAIR $^{17}$ (a downward movement is made twice while moving the hands sideward from left to right).

Sideward reduplication is also the main pluralization strategy for L-nouns as exemplified in Figure 11: the L-noun CHILD is not only repeated but a sideward movement from left to right is also added. For some L-nouns, the sideward reduplication is executed with two hands, i.e. the non-dominant hand is added to the one-handed base noun and both hands then move to opposite sides.
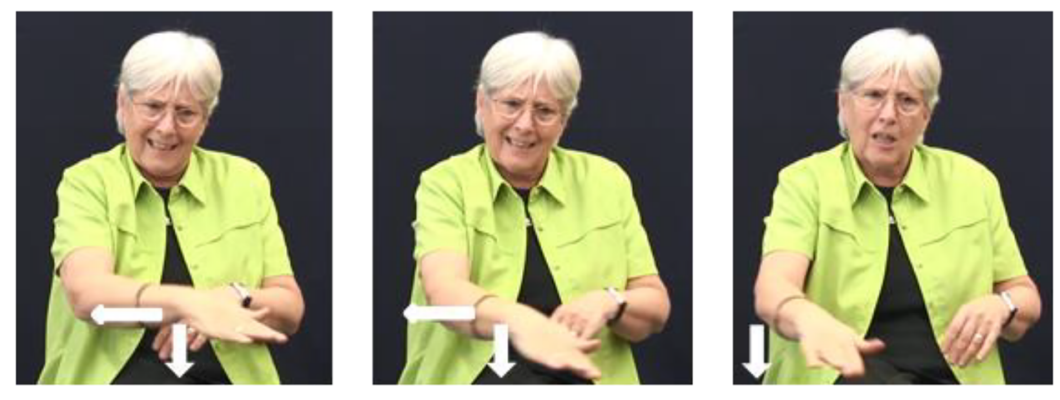

\section{CHILD $>+>+$}

Figure 11: Pluralization of L-noun CHILD by sideward reduplication (a short downward movement is made three times while moving the hand sideward from signer's left to right) [CNGT008; 00:52.040].

17 M-noun CHAIR in Figure 10 has a slightly different form than in Figure 9a, as there is a difference in palm orientation. 
More generally, it can be concluded that all non-body-anchored nouns with a simple movement (both $\mathrm{L}$ and $\mathrm{M}$ ) can undergo sideward reduplication. On the other hand, B-nouns and C-nouns cannot undergo sideward reduplication in NGT and they are statistically more likely to be zero-marked.

Finally, an alternative strategy that is observed for L-nouns and one-handed B-nouns (subsumed under 'others' in Table 4), but only infrequently, is articulating the base noun simultaneously with two hands. This addition of the non-dominant hand could be labelled as 'simultaneous reduplication'. This is exemplified in Figure 12, where the L-noun CHILD, which is one-handed in its base form, is articulated with two hands to indicate plurality, without additional repetition.

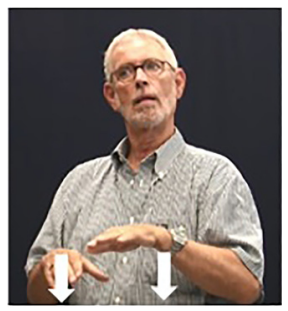

CHILD $(\operatorname{sim} 2 \mathrm{~h})$

Figure 12: Pluralization by articulating the one-handed base noun CHILD (L-noun) with two hands without repetition and fully simultaneously [CNGT0099; 00:42.960].

Note that some nouns occur with multiple strategies. For instance, CHILD is an L-noun and is thus usually pluralized by means of sideward reduplication, as in Figure 11, but in some instances it occurs with zero marking, or it is articulated with two hands (Figure 12). At least in the elicited data, this type of variation is observed both within and across participants.

\subsection{The presence of numerals and quantifiers}

In a total of 47 of the analyzed corpus hits and $109^{18}$ of the elicited sentences, the plural noun is accompanied by a numeral or a quantifier. With respect to zero marking, no significant difference was found between sentences with and

18 Despite the instructions, participants sometimes added numerals or quantifiers to their answers that were not in the carrier sentences, and sometimes they omitted or changed numerals/ quantifiers that were in the carrier sentences. Therefore, the total number is 109 sentences, instead of 105 , as would be expected, given that there were 105 carrier sentences (21 per participant) that contained numerals/quantifiers. 
without numerals/quantifiers ( $p=0.83)$, and there was also no significant effect of data type $(p=0.14)$. Thus, the statistical analyses provide no evidence whether numerals/quantifiers would block plural marking in NGT (an overview of all statistical data for the fixed effects is provided in Appendix D).

Still, we can have a closer look at both data sets, where numerals/quantifiers sometimes co-occur with simple reduplication $(N=9$ in the corpus data, $N=43$ in the elicited data) and sometimes with sideward reduplication $(N=24$ in the corpus data, $N=27$ in the elicited data). For instance, in (4a), the L-noun wEEK is reduplicated (sideward), even though preceded by a numeral, and in (4b), the B-noun HUMAN is reduplicated (simple), even though preceded by a quantifier.

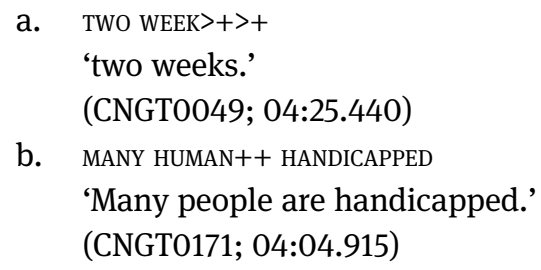

Thus, unlike in DGS (Pfau and Steinbach 2006) and some spoken languages such as Hungarian (e.g. Ortmann 2000), reduplication can co-occur with numerals/ quantifiers. That is, NGT allows for NP-internal number agreement - at least optionally since in the remaining sentences the noun co-occurring with the numeral/quantifier is not marked for plurality ( $N=14$ in the corpus data, $N=39$ in the elicited data). In (5a), the B-noun PROBLEM is zero-marked, and plurality is only indicated by means of the quantifier. In sentences without numerals/quantifiers, PROBLEM was sometimes reduplicated. However, it cannot be concluded that the quantifier blocked reduplication; no significant effect was found, and furthermore, some nouns are also zero-marked when they are not preceded by a numeral/ quantifier, as shown in (5b), where the same noun is zero-marked in a sentence without a numeral/quantifier. There were no instances in which PROBLEM was reduplicated and co-occurred with a numeral/quantifier.

(5) a. FEW PROBLEM

'There are few problems.'

(CNGT1684; 00:42.760)

b. [...] INDEX 3 3a SELF PSYCHOLOGY PROBLEM $[\ldots]$

'[The child] could develop psychological problems.'

(CNGT0132; 03:06.040) 
Moreover, for other nouns, such as the L-noun wEEK, the numeral/quantifier sometimes occurs with zero marking, but not always; compare (6), where this noun is zero-marked and plurality is marked only by means of the numeral, to (4a), where plurality is marked both on the noun and by the numeral. Thus, there is variation in the corpus data that cannot be explained by the presence of numerals/ quantifiers alone.

(6) ALSO ONE time go.to America two WeEk

'One time, I also went to America for two weeks.'

(CNGT0386; 02:13.600)

In fact, for only nine of the elicited sentences with a numeral/quantifier and zero marking, the noun was reduplicated by the same participant in the corresponding sentence without the numeral/quantifier. In those instances, the reduplication may have been blocked; this is illustrated in (7). In (7a), the participant reduplicates the $\mathrm{C}$-noun BABY; there is no numeral/quantifier in the sentence. Yet, in (7b), the same noun is preceded by the quantifier MANY, and the participant does not reduplicate BABY. Possibly, many blocked the reduplication because the plural is already marked by the quantifier, and thus pluralization of the noun is redundant $(7 \mathrm{~b})$ even though in principle BABY can undergo reduplication (7a).

(7) a. ALSO PRESENT BABY+

'Babies also come [to daycare].'

(p03)

b. MANY BABY OFTEN CRY

'Many babies cry often.'

(p03)

\subsection{Accounting for the number of repetitions}

\subsubsection{Individual variation}

In total, 215 noun tokens extracted from the corpus and 115 elicited noun tokens were reduplicated. Recall that previous research has shown that the number of repetitions in sign language reduplication may be subject to individual variation and be influenced by various factors (e.g. Pfau and Steinbach 2006; 
Zwitserlood and Nijhof 1999). Moreover, Pfau and Steinbach (2006: 157) note that "triplication, while being rare across spoken languages, is a common feature in the morphosyntax of sign languages. Various types of aspectual modification, for instance, also involve triplication (or even more repetitions)". Therefore, the number of repetitions ${ }^{19}$ in reduplicated NGT nouns was analyzed, as shown in Table 5.

Table 5: Number of repetitions in reduplication in the corpus and elicited data.

\begin{tabular}{lrrrrrrrr}
\hline & \multicolumn{7}{c}{ Number of repetitions } \\
\cline { 2 - 8 } & Total & < One & One & Two & Three & Four & Unclear \\
\hline Simple reduplication & 133 & 19 & 90 & 14 & 2 & 1 & 7 \\
Sideward reduplication & 197 & 1 & 78 & 44 & 4 & 1 & 69 \\
\hline
\end{tabular}

The table reveals that although the number of repetitions varies, the majority of both reduplication types involves only one repetition. Thus, although triplication (i.e. two repetitions) does occur, duplication still occurs more frequently. Often, the movement repetitions are articulated in rapid succession. Especially in sideward reduplication, the movement is sometimes too reduced to actually count the number of repetitions: the base noun and the reduplicants are then fused into one extended, sideward, movement. In those cases, I annotated 'unclear' since the different reduplicants were not distinguishable. It is likely that the amplitude of movement reduces when number of repetitions increases, however, I leave this matter for future studies because this was not systematically annotated.

As the table shows, the number of repetitions is subject to (individual) variation, and, with few exceptions (eight in total), nouns are usually not repeated more than twice. The same variation is also attested in signs that are lexically specified for repetition. A possible explanation is that the number of (inherent) repetitions may vary depending on the position of the sign within a prosodic domain, as Nespor and Sandler (1999) found for Israeli Sign Language. Here, the potential impact of prosodic structure will not be further explored.

It should be noted that in both data sets, the number of repetitions does not usually reflect the exact number of referents. For example, in (8a), the signer repeats the L-noun variant of LAMP only once even though the elicitation picture showed three lamps and the numeral THREE was present in the carrier sentence. Yet, there are also cases in which it seems that the number of repetitions mirrors the actual number

19 The base is not included in the number of repetitions, i.e., BASE-REDUPLICANT-REDUPLICANT is analyzed as two repetitions. 
of referents. For instance, in (8b), the same variant of LAMP is repeated twice, i.e. in total, three instances of LAMP were articulated, thus matching both the elicitation picture and the accompanying numeral. In cases like this, there appears to be an emphasis on 'not more or less than three' because each movement repetition is articulated with emphasis and the number of repetitions is not arbitrary.

(8) a. INDEX 1 BUY THREE NEW LAMP>+

'I buy three new lamps.'

(p05)

b. INDEX 1 THREE NEW LAMP $>+>+$ BUY

'I buy three new lamps.'

(p04)

\subsubsection{The impact of mouthings}

Next, it was considered whether there is a correlation between the number of repetitions and the number of syllables in the accompanying mouthing as had been suggested previously by Zwitserlood and Nijhof (1999) (see also Boyes Braem 2001; Sandler 1999). Indeed, a considerable number of nouns - 362 in total - from both data sets are accompanied by mouthings: 152 (80.4\%) elicited nouns and 210 (70.7\%) corpus nouns. This is not surprising given that previous research has shown that mouthings occur frequently in NGT since they make up the largest part of mouth actions in the language (Bank 2015). For the other 37 elicited noun tokens $(19.6 \%)$ and 87 corpus noun tokens (29.3\%), there is either no mouthing, or the mouthing is unclear or not completely visible.

There was a significant positive association between number of repetitions in the noun and the number of syllables in the accompanying mouthing $(r(361)=0.2$, $p<0.001,95$ percent confidence interval from 0.1 to 0.29) (see also Appendix D). Thus, nouns that were accompanied by mouthings with more syllables were repeated more often.

For the most part, Dutch plurals contain more syllables than the corresponding singular noun, and this may be reflected in the mouthings accompanying nouns. Indeed, 85 elicited noun tokens and 69 noun tokens from the corpus are accompanied by an articulation of the corresponding Dutch noun in its plural form (44.9\% and $23.26 \%$ respectively of nouns accompanied by mouthings in the data). In (9a), for instance, the L-noun chILD is not only reduplicated, but the plural Dutch word kinderen 'children' /kindərə/ is also mouthed - note that here, the mouthing has three syllables, and there are two repetitions (i.e. hand and mouth are synchronized). Still, on the other hand, in 63 elicited instances and 135 corpus instances (33.3\% and 45.5\% respectively of 
nouns accompanied by mouthings in the data), (a part of) the corresponding singular Dutch word is mouthed: in (9b), the B-noun variant of LAmp is reduplicated but is accompanied by the mono-syllabic Dutch singular word lamp 'lamp' /lamp/.

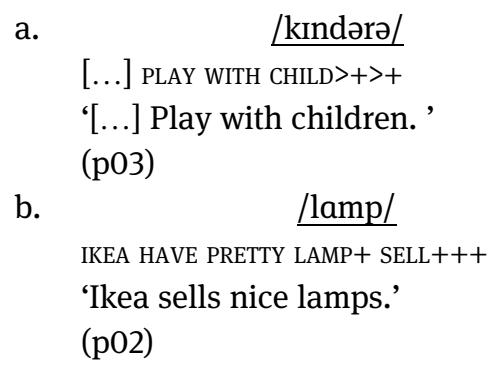

a.

/kindərə/

[...] PLAY WITH CHILD $>+>+$

'[...] Play with children.'

(p03)

b. /lamp/

IKEA HAVE PRETTY LAMP+ SELL+++

'Ikea sells nice lamps.'

(p02)

Strikingly, besides mouthing of the Dutch singular or plural word, another form of mouthings was found, albeit infrequently: three elicited noun tokens and two corpus noun tokens are accompanied by a reduplicated articulation of the Dutch singular noun, despite reduplication not being a productive morphological process in Dutch. This is illustrated in (10a), where the reduplicated B-noun HUMAN is accompanied by a repeated articulation of the Dutch singular mens 'human' /mens/ (thus, lit. 'human human'). Similarly, one elicited plural noun, the M-noun TROUSERS, was accompanied by a reduplicated articulation of a verb (10b). First, the noun is articulated manually and is accompanied by the corresponding singular mouthing broek 'trousers(sG)' /bruk/. Subsequently, TROUSERS is reduplicated sidewards, and is accompanied by a repeated articulation of the Dutch verb pas /pas/ (infinitive passen 'to try on'). We are thus dealing with an instance of code-blending, that is, a simultaneous mixing of sign and spoken language (Emmorey et al. 2005). This exemplifies the tendency of hand and mouth movement to align, as described above, since in these reduplicated mouthings the number of non-manual repetitions (i.e. syllables) is synchronized with the number of movement repetitions (including the movement of the base). Finally, the remaining four corpus instances contain some other mouthing (e.g. an adjective).

a.

$\underline{\text { /mens mens/ }}$

'Children are human too.'

(CNGT0333; 00:37.600)

b.

/bruk/ Lpas pas pas pas/

INDEX 1 YESTERDAY SHOP GO. TROUSERS TROUSERS $>+>+>+$

'Yesterday I went shopping. I tried on (several pairs of) trousers.' (p01) 
Note that marking the plural only by means of a mouthing might be considered a separate pluralization strategy since in 18 of the elicited sentences and seven of the corpus sentences the noun is zero-marked yet accompanied by a plural mouthing, as in (11) where TROUSERS is not reduplicated yet accompanied by the Dutch plural broeken 'trousers(PL)' /brukə/.

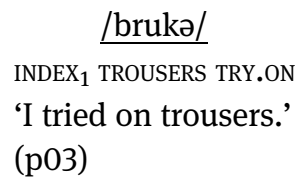

\subsection{Other pluralization strategies}

The elicited data make clear that plurality can also be marked on elements other than the noun - be it in combination with nominal reduplication or not. This section discusses the strategies that were identified, as one of the aims was to provide a comprehensive overview of pluralization strategies in NGT. First, some other element in the sentence may be reduplicated. This may be the verb, as observed in eleven sentences (in nine of these, there is zero marking on the noun; in the other two, the noun is also reduplicated). This is illustrated in (12) where the noun is zero-marked but the verb TRY.ON is reduplicated. Moreover, in four sentences, the sign INSIDE is modified by means of sideward reduplication, always combined with a zero-marked noun as illustrated in Figure 13; here, we see zero marking on the C-noun SHOP, followed by sideward reduplication of INSIDE.

$$
\begin{aligned}
& \text { INDEX }_{1} \text { MANY TROUSERS TRY.ON+++ } \\
& \text { 'I tried on many [pairs of] trousers.' } \\
& \text { (p02) }
\end{aligned}
$$
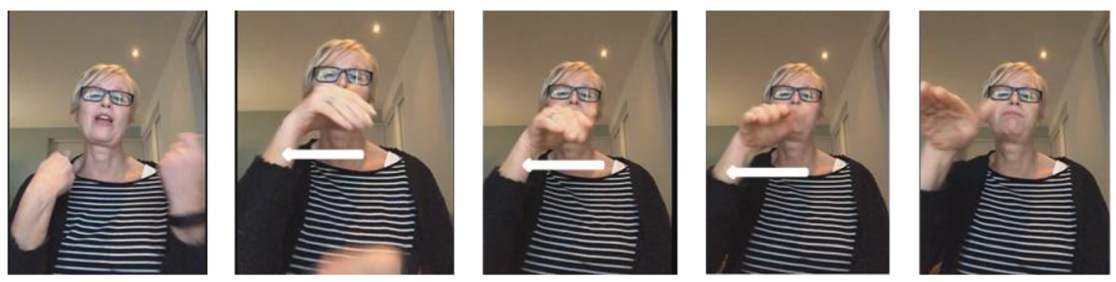

SHOP INSIDE $>+>+>+$

Figure 13: Zero-marked C-noun SHOP followed by several instances of INSIDE, executed with sideward movement; the translation is: 'in shops'. 
Furthermore, six nouns are followed by a classifier which is reduplicated sideward (in only one case, the noun is also reduplicated): in Figure 14, the C-noun CAR is zero-marked and is followed by a classifier indicating a small object, also reduplicated sideward. This classifier is used to indicate that the signer is referring to toys (i.e. small) cars, rather than real ones.
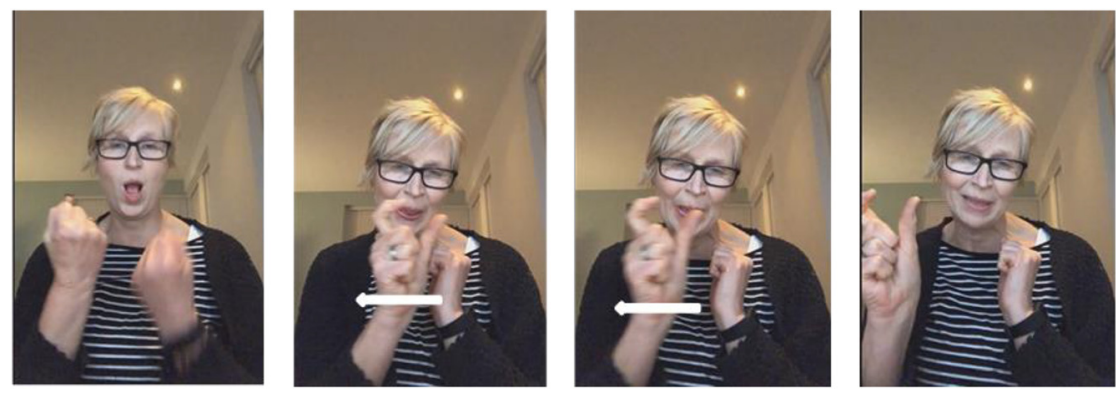

CAR CLSMALL-OBJECT $>+>+$

Figure 14: Zero-marked C-noun CAR followed by a classifier indicating a small object, executed with one, reduced sideward movement; the translation is: 'toy cars'.

Finally, for human (or, possibly, animate) referents, there appears to be an additional strategy to indicate plurality: in eight cases, when localizing a plural referent in signing space, this is not done by a 'regular' pointing sign in space (INDEX), but rather by an arc-shaped indexical sign. This strategy can be used in combination with both reduplicated (six cases) and zero-marked (two cases) nouns. In Figure 15, the B-noun woman is reduplicated and then localized in space by means of an $\operatorname{INDEX}_{\mathrm{ARC}}$.
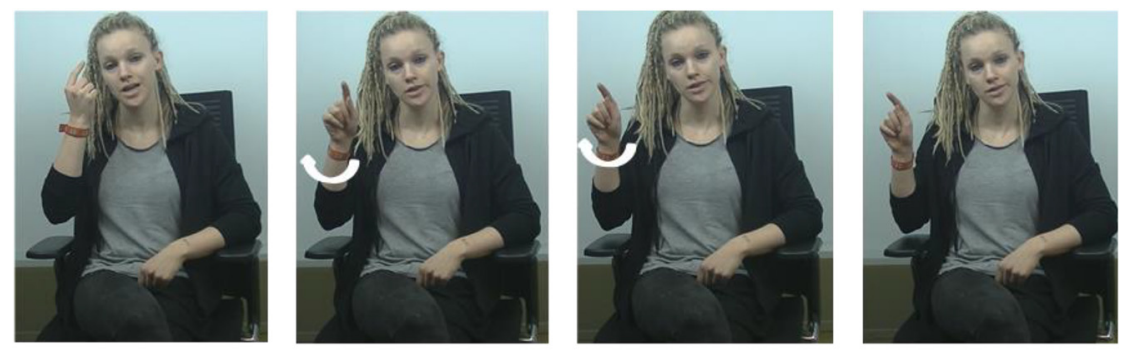

WOMAN++ INDEX $\mathrm{ARC}$

Figure 15: Pluralization by reduplication of B-noun wOMAn followed by arc-shaped INDEX; the translation is: 'women'. 


\section{Discussion}

To summarize, the results suggest that the pure plural form in NGT can be marked by simple reduplication and sideward reduplication and that the phonological noun type influences the choice between the two. However, these processes are optional, and there is considerable variation in the data. Statistical analyses show that $\mathrm{C}$ - and B-nouns are more likely to be zero-marked than $\mathrm{M}$ - and L-nouns, and that there is a positive correlation between the number of syllables in the mouthing and the number of repetitions.

These findings thus complement previous research on NGT by disentangling pluralization from spatial distribution, which is discussed in further detail in Section 5.1. The range and impact of the variation attested in the NGT data is the focus of Section 5.2. Finally, the phonological restrictions on reduplication found for NGT are compared to those described for other sign languages in Section 5.3.

\subsection{Disentangling pluralization from spatial distribution}

The novel gap-filling task succeeded in disentangling pluralization from localization and as such yielded valuable data that complement previous findings: it revealed that - in addition to the pluralization strategies previously described by Zwitserlood and Nijhof (1999) - nominal reduplication commonly occurs in NGT. The task offers an elegant alternative way to investigate plurality without the pitfalls of a picture description task. Similar gap-filling tasks could fruitfully be used in future research into different topics where the use of space needs to be controlled for. Of course, if the research topic involves spatial configuration, a picture description task is more useful.

Additional evidence that the task succeeded in disentangling pluralization from localization comes from the fact that the spatial arrangements of the objects shown on the picture stimuli did not influence the choice of pluralization strategy. If this were the case, we would expect referents presented in a neat row to be pluralized by means of sideward reduplication. However, since the spatial arrangements shown on the pictures were not relevant in the sentence contexts, this did not happen. To give an example, the L-noun воттLE was pluralized by means of sideward reduplication even though the bottles on the picture were not presented in a neat row but were arranged randomly rather. Conversely, the B-noun wOMAN was pluralized by means of simple reduplication, even though the women on the picture were standing in a row. This suggests that while phonological 
characteristics of the base noun play a role in the choice of the pluralization strategies, the spatial arrangement of the referents does not.

One might hypothesize that the focus on pluralization in the experiment increased the frequency of use of plural marking in the elicited data. Yet, this was not the case: while $74.4 \%$ of the nouns in the corpus data undergo overt pluralization, this is the case for only $61.9 \%$ of the elicited nouns. Indeed, zero marking occurs more often in the elicited data, which suggests that the experiment did not enhance frequency of reduplication to a large extent. I further refer to van Boven (2020) for an elaborate consideration of the advantages and disadvantages of such a gap-filling task.

A related point is that simple and sideward reduplication and zero marking are likely not to be the only ways to express 'pure' plurals in NGT. I also found some alternative strategies: (i) nominal strategies that occur only infrequently (simultaneous reduplication of the noun); (ii) non-manual strategies (mouthings); and (iii) strategies that do not affect the noun at all (reduplicating some other element; arc-shaped index). This suggests that NGT has many ways to mark pure plurals, which deserve further investigation. Particularly interesting is the example in Figure 14 above, which suggests that classifiers can also be used to express pure plurality without indicating the spatial distribution of the referents. The reduplicated classifier in this example is used to indicate the size of the cars but it does not represent the spatial distribution of the cars on the stimulus picture (they were presented in a half circle, not in a row). This is striking since the localization of classifiers is usually claimed to be a dedicated strategy for indicating spatial relations, as also found for NGT by Zwitserlood and Nijhof (1999).

Interestingly, a similar use of classifier handshapes to mark 'pure' plurals has recently been described for DGS by Herbert (2018: 124). She describes a so-called "classifier-based plural morpheme" (CLP), which "takes the form of classifier handshapes available in the language, combined with sideward reduplication." Similar to the NGT example in Figure 14, Herbert (2018: 124) describes that the CLP is reduplicated by means of "one continuous, fluid movement, in contrast to the punctuated reduplication typical of a canonical classifier construction.” And, likewise similar to what we observe for NGT, the interpretation of this form is the 'pure' plural, or, as Herbert calls it, the simple plural.

Notably, Herbert states that while canonical classifier constructions can be used with all different nouns, the CLP only combines with nouns that cannot fully realize the canonical plural, which is assumed to be sideward reduplication. If a similar CLP was attested in NGT, as the example in Figure 14 above suggests, we would expect this morpheme to combine with nouns that cannot undergo sideward reduplication, i.e. C- and B-nouns. In the data elicited here, the potential CLP co-occurs with four C-nouns, one B-noun, and one M-noun. The co-occurrence 
with an M-noun is unexpected based on Herbert (2018) because in principle this noun can undergo sideward reduplication; yet, M-nouns sometimes also undergo simple reduplication, which may be an explanation. At least, just as in DGS, the potential CLP does not co-occur with L-nouns in the data here. Future research into a CLP in NGT would certainly be worthwhile.

\subsection{The range and impact of variation}

Regarding reduplication, the discussion so far focused on the most frequent patterns, marked in boldface in Table 4 - simple reduplication of C-, B-, and M-nouns, and sideward reduplication of $\mathrm{M}$ - and L-nouns. However, we should not neglect the fact that these patterns are not categorical: in a small number of cases, B- and C-nouns undergo sideward reduplication, and L-nouns undergo simple reduplication. Although not systematically investigated here, there seem to be explanations for at least some of these exceptions. For instance, some of the L-nouns undergoing simple reduplication already have a sideward movement in their base form (e.g. school). This may cancel out the spatial displacement that characterizes sideward reduplication. Moreover, many B-nouns undergoing sideward reduplication have a lateral location (e.g. one variant of DoLL), which may have influenced the pluralization strategy.

Nevertheless, there is considerable variation in the NGT data, and reduplication is clearly optional. This may raise questions on the grammatical status of reduplication as a pluralization strategy in NGT. Yet, it is important to note that variation in and optionality of morphosyntactic and syntactic marking is a characteristic of many investigated sign languages. Grammatical phenomena that have been shown to display optionality and/or to be subject to intra- and inter-signer variation include agreement marking (De Beuzeville et al. (2009) for Australian Sign Language) and, in the domain of syntax, the position of negative markers (Oomen and Pfau (2017) for NGT) and wh-signs (Geraci et al. (2014) for LIS). Thus, the fact that we also find optionality and variation in NGT plural marking is perhaps not that surprising after all (see Section 5.3 for further discussion).

Interestingly, similar variation is also attested in some spoken languages. Specifically, for the domain of pluralization, Hayes and Abad (1989) describe variation in plural reduplication in Ilokano (a language of the Philippines). Usually, pluralization is realized by heavy reduplication, under which the initial consonant(s), a vowel, and the next consonant of the stem are copied - this is the pattern we observe in (13a). Yet, when the stem starts with a consonant plus glide cluster (as is true for pjano), two alternative options are available (Hayes and Abad 1989, summarized in Boersma and Hayes 2001). The second option is to copy the 
stem-initial consonant plus a long vowel as in (13b). The final option is to copy the first consonant plus a vowel and to create a heavy syllable by resyllabification, as in (13c) (Hayes and Abad 1989, in Boersma and Hayes 2001: 56). Crucially, these three options are in free variation.
a. pja.no pjan.pja.no
'piano' 'pianos'
b. pja.no pi:.pja.no
'piano' 'pianos'
c. pja.no pip.ja.no
'piano' 'pianos'
(Ilokano; Hayes and Abad (1989), in Boersma and Hayes (2001: 56))

Thus, variation in and optionality of morphological marking is common in sign languages, and variation in the realization of reduplication specifically is also attested in a spoken language. This suggests that the variation in the NGT data is not as exceptional as it may at first seem.

\subsection{Language-specific constraints on reduplication}

This study distinguished phonological noun types, which led to the conclusion that there is some systematicity within the variation. Indeed, the choice between simple and sideward reduplication in NGT largely depends on phonological properties of the base noun. Phonologically triggered allomorphy has previously been described for other sign languages. Recall the findings for DGS (Pfau and Steinbach 2005, 2006), summarized in Section 2.3: C-nouns and B-nouns cannot be reduplicated in this language. Similarly, in BSL, while sideward reduplication applies to L-nouns and to (at least some) M-nouns, both B-nouns and C-nouns cannot undergo reduplication (Sutton-Spence and Woll 1999). For LIS, Pizzuto and Corazza (1996: 181) distinguish between "nouns articulated on the body" (i.e. B-nouns) and "neutral-space nouns". For the latter, they argue that nouns with simple movement can undergo sideward reduplication, while, again, C-nouns and B-nouns apparently cannot be reduplicated. Finally, pluralization in ASL is somewhat less restricted since reduplication of some specific B- and C-nouns is permitted (Wilbur 1987).

Thus, in most of the sign languages described to date, reduplication is blocked by certain phonological properties (body-anchoredness and complex movement). The findings here reveal that this is not the case for NGT: while indeed B- and C-nouns rarely undergo sideward reduplication and are more likely to be zero-marked than M- and L-nouns, simple reduplication is not 
blocked altogether for these noun types. That is, reduplication in this language appears less constrained because all noun types can undergo at least one type of reduplication. NGT patterns with ASL in this respect although my data do not indicate that only specific B- and C-nouns undergo reduplication; perhaps NGT pluralization is even less restricted than ASL pluralization. Moreover, Pfau and Steinbach (2005) suggest that nouns that can be reduplicated in DGS are never zero-marked. Again, NGT behaves differently: zero marking occurs with all noun types.

Possibly, it is not (only) the phonological properties of the noun that block reduplication in NGT; perhaps we should attend to other properties to explain the occurrence of zero marking. Interestingly, a reviewer brings to my attention that in, for instance, BSL, iconicity constrains reduplication. More specifically, signs whose form bears a metonymic relationship with their referents have been reported to be blocked from undergoing reduplication; a case in point is the BSL sign CAR, which represents turning the steering wheel - similar to the NGT sign CAR (Figure 5a). Given this suggestion, I checked the data to scrutinize whether metonymy might also explain the occurrence of zero marking in NGT. The data set did not include many signs that are clearly motivated by metonymy. One clear case is the NGT sign CAR; as already clear from Figure 9c, this sign can actually be reduplicated. Other, albeit less clear, examples are BIKE, GIRL and TRAIN - these, too, were found to undergo reduplication. This suggests that metonymy does not block reduplication in NGT, in contrast to BSL.

A potential explanation for the cross-linguistic differences was explored by looking at the historical links between the sign languages described above, as described by Power et al. (2020). On the one hand, restrictions on reduplication in NGT pattern with those described for ASL: both these languages are traceable to Old French Sign Language and are indeed classified in the French-origin group by Power et al., suggesting that this common link may explain why reduplication is less restricted than was reported for other languages, for instance BSL, which is part of the British-origin group. On the other hand, B- and C-nouns cannot be reduplicated in LIS, a language that can also be traced back to the French-origin group. Similarly, Power et al. note that contemporary DGS, originally classified in the Austrian-origin group, is now also found in the French-origin group. This suggests that historical links between sign languages alone cannot fully explain why NGT/ASL reduplication is less restricted. This matter should be investigated further by looking at phonological restrictions on nominal reduplication across the different sign language families.

Another potential explanation for cross-linguistic differences can be found in the methodology of the studies. Studies that report rather clear, categorical patterns, such as Pfau and Steinbach (2005), often do not indicate how exactly 
their data were collected. Since the present study takes into account naturalistic corpus data, less clear patterns and more variation are to be expected because corpus data come closer to naturalistic language use than elicited data (other studies that report (morpho)syntactic variation and optionality in sign languages, mentioned above, also investigate corpus data, e.g. De Beuzeville et al. 2009; Oomen and Pfau 2017). However, even in our elicited data, all noun types optionally undergo at least one type of reduplication. This suggests that these findings are persistent in NGT.

While all noun types in NGT can undergo at least one type of reduplication, it has to be emphasized that this does not mean that all strategies apply to all noun types: phonological properties of the base noun may not block reduplication but they do influence the reduplication type. The present study is thus an important contribution to the typology of reduplication in sign languages. Clearly, reduplication, despite being iconically motivated, is subject to language-specific grammatical constraints.

\section{Conclusion}

This study presented a description of nominal pluralization in NGT, taking into account potential phonological restrictions. First, analysis of corpus and elicited data revealed three main pluralization strategies: simple reduplication, sideward reduplication, and zero marking. Second, it turned out that phonological allomorphy plays an important role. While C-nouns and B-nouns are more likely to be zero-marked than the other noun types, they can undergo simple reduplication, while L-nouns undergo sideward reduplication. Finally, M-nouns can undergo both simple and sideward reduplication. Reduplicating the noun is not obligatory since zero marking occurs quite often with all noun types.

Notably, reduplication is also found to be a common pluralization strategy in other sign languages, as it is in spoken languages. Yet, the results presented here show that nominal reduplication is subject to language-specific phonological constraints. While body-anchoredness and complex movement have been noted to block reduplication in other sign languages, this is not the case for NGT. Phonological properties of the base noun influence the type of reduplication (i.e. simple or sideward) but do not block it altogether. Moreover, the patterns in the NGT data are not as categorical as those reported for other sign languages because there is considerable variation for all noun types. Yet, variation in plural reduplication has also been attested in at least one spoken language (Ilokano; Hayes and Abad 1989). 
Some issues regarding nominal pluralization in NGT are left for further research. First, the number of repetitions in reduplication varies greatly, and there is a positive correlation with the number of syllables in the mouthing. Future research could look into further (prosodic) factors that might play a role here. Moreover, the influence of numerals and quantifiers on marking the plural on the noun remains unclear; no statistical effect is found. Further investigation into DP-internal number agreement is necessary. Finally, it appears that the plural can also be marked on elements other than the noun - for instance, reduplication of the verb. Future research can look into these different strategies, and which strategy is preferred. That is, the present study focused on plural marking on the noun sign, but it is possible that when focusing on pluralization more broadly, the preferred strategy is on elements other than the noun.

To conclude, this study offers a description of new NGT data, complementing previous findings in important ways. A subsequent study will aim to formalize these results in an Optimality-Theoretic framework, offering a constraint-based analysis of nominal reduplication in NGT (van Boven et al. under review).

Acknowledgements: I would like to express my gratitude to all signers who participated in this study, as well as to Roland Pfau, Natalia Rivera-Vera, Marijke Scheffener, and Silke Hamann for all their help. I also thank two anonymous reviewers for their comments and suggestions.

Research funding: This work is part of the research programme PhDs in the Humanities with project number PGW19.003, funded by the Dutch Research Council (NWO).

\section{Appendix A: Glossing conventions for sign lan- guage examples}

\begin{tabular}{|c|c|}
\hline SIGN & The gloss of one single sign \\
\hline SIGN.SIGN & Multiple words form the gloss of one single sign \\
\hline SIGN ++ & Simple reduplication of a sign; number of pluses indicates number of repetitions \\
\hline SIGN>+ & Sideward reduplication of a sign; number of pluses indicates number of repetitions \\
\hline INDEX & $\begin{array}{l}\text { Pointing sign with a linguistic function (pronoun); subscript number refers to loca- } \\
\text { tions in the signing space }(1=\text { chest of signer; } 3 \mathrm{a} / 3 \mathrm{~b}=\text { right or left in signing space; } \\
\text { arc = index articulated with arc-shaped movement) }\end{array}$ \\
\hline $\mathrm{CL}$ & Classifier sign \\
\hline 1 & Mouthing (phonological form); line indicates the scope \\
\hline $\begin{array}{l}\text { (CNGTx; } \\
\mathrm{xx})\end{array}$ & Corpus NGT file number + begin time (m:s.ms) \\
\hline
\end{tabular}




\section{Appendix B: Annotation values}

\begin{tabular}{|c|c|}
\hline Tier name & Annotation values \\
\hline Noun & the Dutch gloss of the analyzed noun \\
\hline \multirow[t]{8}{*}{ Noun type } & $\mathrm{C}$ \\
\hline & $\mathrm{C}[\mathrm{circ}]$ \\
\hline & C[alt $]$ \\
\hline & $\mathrm{C}[$ circ] $]$ alt $]$ \\
\hline & $\mathrm{B}$ \\
\hline & $\mathrm{B}[$ contact $]$ \\
\hline & M \\
\hline & L filler \\
\hline Pluralization strategy & $\begin{array}{l}\text { zero marking simple reduplication sideward reduplication } \\
\text { other }\end{array}$ \\
\hline Number of repetitions & $\begin{array}{l}<1,1,2,3 \text {, etc. if the movement of the base and reduplicant(s) } \\
\text { was reduced/merged into one, long movement: unclear }\end{array}$ \\
\hline Numeral/quantifier & $\begin{array}{l}\text { the Dutch gloss of the numeral/quantifier(s) present in the } \\
\text { sentence }\end{array}$ \\
\hline $\begin{array}{l}\text { Reduplication blocked by nu- } \\
\text { meral/quantifier? }\end{array}$ & yes, no \\
\hline Base one-/two-handed & 1-handed, 2-handed \\
\hline Plural one-/two-handed & 1-handed, 2-handed \\
\hline Mouthing & $\begin{array}{l}\text { Dutch word or part of word that is mouthed, orthographic form, } \\
\text { e.g. 'lampen' (lamps) if not visible/clear: unclear }\end{array}$ \\
\hline Comments & any additional comments \\
\hline
\end{tabular}




\section{Appendix C: Nouns across noun types in the corpus and elicited data}

\begin{tabular}{|c|c|c|}
\hline Noun types & Nouns & \\
\hline \multirow[t]{11}{*}{ B-nouns (types: 26) } & PERSON(variant 1) & TROUSERS(variant 1) \\
\hline & COUNTRY & MOVIE \\
\hline & HUMAN & PILLow(variant 1 , variant 2) \\
\hline & CONTACT & LAMP(variant 1) \\
\hline & MAN & GIRL \\
\hline & WOMAN & FRIEND \\
\hline & PROBLEM & SHOP \\
\hline & MOTHER & нотец(variant 1, variant 2) \\
\hline & FARMER & MOUSE(variant 1, variant 2) \\
\hline & GLASSES & DoLL(variant 1 , variant 2 , variant 3 ) \\
\hline & DAY & \\
\hline \multirow[t]{5}{*}{ L-nouns (types: 10) } & ADULT & PERSON(variant 2) \\
\hline & CHILD & SCHOOL \\
\hline & FLAG & PART \\
\hline & WEEK & вотtLE(variant 1) \\
\hline & THING & LAMP(variant 2) \\
\hline \multirow[t]{5}{*}{ M-nouns (types: 9) } & HOUSE & BOTTLE(variant 2) \\
\hline & воОк & CHAIR \\
\hline & BUILDING & нотеL(variant 3) \\
\hline & WORD & OFFICE \\
\hline & TROUSERS(variant 2) & \\
\hline \multirow[t]{3}{*}{ C-nouns (types: 6) } & INPUT & BABY \\
\hline & TRAIN & BICYCLE \\
\hline & CAFé & CAR \\
\hline
\end{tabular}

\section{Appendix D: Overview of results from the statisti- cal analyses}

\begin{tabular}{llrrrr}
\hline Predictor & Estimate & Odds ratio & 95\% CI & Z & $p$ \\
\hline Noun type (-BLM+C) & 0.63 & 1.87 & $0.86-4.04$ & 1.59 & 0.11 \\
Noun type (-LM+BC) & 2.33 & 10.24 & $3.49-30.06$ & 4.23 & $<0.001^{*}$ \\
Noun type (-CLM+B) & rank deficient & & & & \\
Data type (-corpus+elicited) & 0.21 & 1.23 & $0.63-2.4$ & 0.61 & 0.54 \\
\hline
\end{tabular}

Model 1: Zero Noun_type + Data_type + (Noun_type | Participant). Significant findings $(p \leq 0.05)$ are indicated by an asterisk (*). 


\begin{tabular}{lrrrrr}
\hline Predictor & Estimate & Odds ratio & 95\% CI & $\boldsymbol{z}$ & $\boldsymbol{p}$ \\
\hline Presence of numeral/quantifier (-no+yes) & 0.06 & 1.07 & $0.6-1.89$ & 0.22 & 0.83 \\
Data type (-corpus+elicited) & 0.51 & 1.67 & $0.84-3.31$ & 1.47 & 0.14 \\
\hline
\end{tabular}

Model 2: Zero $\sim$ Num + Data_type + (Num | Participant). Significant findings ( $p \leq 0.05)$ are indicated by an asterisk $\left(^{\star}\right)$.

\begin{tabular}{rrrrrr}
\hline Pearson's $\boldsymbol{R}$ & $95 \% \mathrm{Cl}$ & $\boldsymbol{D f}$ & $\boldsymbol{t}$ & $\boldsymbol{p}$ \\
\hline 0.2 & $0.1-0.29$ & 361 & 3.83 & $<0.001^{\star}$ \\
\hline
\end{tabular}

Model 3: Pearson correlation between Number of repetitions and Syllables in mouthing. Significant findings $(p \leq 0.05)$ are indicated by an asterisk $\left(^{*}\right)$.

\section{References}

Aronoff, Mark, Irit Meir \& Wendy Sandler. 2005. The paradox of sign language morphology. Language 81(2). 301-344.

Bank, Richard. 2015. The ubiquity of mouthings in NGT: A corpus study. Utrecht: Radboud University Dissertation.

Barr, Dale J., Roger Levy, Christoph Scheepers \& Harry J. Tily. 2013. Random effects structure for confirmatory hypothesis testing: Keep it maximal. Journal of Memory and Language 68(3). 255-278.

Bates, Douglas, Martin Mächler, Benjamin M. Bolker \& Steven C. Walker. 2015. Fitting linear mixed effects models using Ime4. Journal of Statistical Software 67(1). 1-48.

Boersma, Paul \& Bruce Hayes. 2001. Empirical tests of the gradual learning algorithm. Linguistic Inquiry 32(1). 45-86.

van Boven, Cindy. 2020. Fill the gap: A novel test to elicit nominal plurals in Sign Language of the Netherlands. FEAST. Formal and Experimental Advances in Sign Language Theory 3. 56-67.

van Boven, Cindy, Silke Hamann \& Roland Pfau. Nominal plurals in Sign Language of the Netherlands: Accounting for allomorphy and variation, under review.

Boyes Braem, Penny. 2001. Functions of the mouthing component in the signing of deaf early and late learners of Swiss German Sign Language. In Diane Brentari (ed.), Foreign vocabulary in sign languages: A cross-linguistic investigation of word formation, 1-47. Mahwah, NJ: Erlbaum.

Boyes Braem, Penny \& Rachel Sutton-Spence (eds.). 2001. The hands are the head of the mouth. The mouth as articulator in sign languages. Hamburg: Signum Press.

Brentari, Diane. 1998. A prosodic model of sign language phonology. Cambridge, MA: The MIT Press.

Crasborn, Onno \& Han Sloetjes. 2008. Enhanced ELAN functionality for sign language corpora. In Onno Crasborn, Thomas Hanke, Eleni Efthimiou, Inge Zwitserlood \& Ernst Thoutenhoofd (eds.), Construction and exploitation of sign language corpora: $3 r d$ Workshop on the Representation and Processing of Sign Languages, 39-43. Paris: ELDA. 
Crasborn, Onno \& Inge Zwitserlood. 2008. The Corpus NGT: An online corpus for professionals and laymen. In Onno Crasborn, Thomas Hanke, Eleni Efthimiou, Inge Zwitserlood \& Ernst Thoutenhoofd (eds.), Construction and exploitation of sign language corpora: $3 r d$ Workshop on the Representation and Processing of Sign Languages, 44-49. Paris: ELDA.

Crasborn, Onno, Richard Bank, Inge Zwitserlood, Els van der Kooij, Anne Meijer \& Anna Sáfár. 2015. Annotation conventions for the Corpus NGT. https://www.ru.nl/corpusngtuk/ methodology/annotation/ (accessed 23 April 2020).

Crasborn, Onno, Inge Zwitserlood \& Johan Ros. 2008. The Corpus NGT: A digital open access corpus of movies and annotations of Sign Language of the Netherlands. http://hdl.handle. net/hdl:1839/00-0000-0000-0004-DF8E-6 (accessed 26 March 2020).

De Beuzeville, Louise, Trevor Johnston \& Adam Schembri. 2009. The use of space with indicating verbs in Auslan: A corpus-based investigation. Sign Language \& Linguistics 12(1). 53-82.

Dutch Language Institute. 2014. Frequentielijsten corpora [Frequency lists corpora] (version 4.0.1) [data set]. http://hdl.handle.net/10032/tm-a2-f8 (accessed 12 March 2020).

Emmorey, Karen, Helsa B. Borinstein \& Robin Thompson. 2005. Bimodal bilingualism: Codeblending between spoken English and American Sign Language. In James Cohen, Kara T. McAlister, Kellie Rolstad \& Jeff MacSwan (eds.), ISB4: Proceedings of the 4th International Symposium on Bilingualism, 663-673. Somerville: Cascadilla Press.

Fenlon, Jordan, Kearsy Cormier \& Diane Brentari. 2017. The phonology of sign languages. In Stephen J. Hannahs \& Anna R. K. Bosch (eds.), The Routledge handbook of phonological theory, 453-475. London: Routledge.

Gamer, Matthias, Jim Lemon, Ian Fellows \& Puspendra Singh. 2019. Various coefficients of interrater reliability and agreement (version 0.84.1). https://CRAN.R-project.org/ package=irr (accessed 31 August 2021).

Geraci, Carlo, Robert Bayley, Anna Cardinaletti, Carlo Cecchetto \& Caterina Donati. 2014. Variation in Italian Sign Language (LIS): The case of wh-signs. Linguistics 53(1). 125-151.

Halvorsen, Rolf Piene, Odd-Inge Schröder, Britta Barman Wold \& Bogumila Schröder. 2014. Noun and plural constructions in Norwegian Sign Language. Manuscript.

Harder, Rita, Corline Koolhof \& Trude Schermer. 2003. Meervoud in de NGT: Verslag van een onderzoek in het kader van OCW subsidie 2003 [Plurality in NGT: Report of a study in the context of OCW subsidy 2003]. https://www.gebarencentrum.nl/publicaties (accessed 7 July 2021).

Hayes, Bruce \& May Abad. 1989. Reduplication and syllabification in llokano. Lingua 77(3-4). 331-374.

Herbert, Marjorie. 2018. A new classifier-based plural morpheme in German Sign Language (DGS). Sign Language \& Linguistics 21(1). 115-136.

van der Hulst, Harry. 1993. Units in the analysis of signs. Phonology 10(2). 209-241.

Jones, Vanessa L. 2013. Numeral incorporation in American Sign Language. Grand Forks, ND: University of North Dakota MA thesis.

van der Kooij, Els. 2002. Phonological categories in Sign Language of the Netherlands: The role of phonetic implementation and iconicity. Leiden: Leiden University Dissertation.

Ktejik, Mish. 2013. Numeral incorporation in Japanese Sign Language. Sign Language Studies 13(2). 186-210.

Liddell, Scott K. \& Robert E. Johnson. 1989. American Sign Language: The phonological base. Sign Language Studies 64. 195-278. 
Mandel, Mark. 1977. Iconic devices in American Sign Language. In Lynn A. Friedman (ed.), On the other hand: New perspectives on American Sign Language, 57-107. New York: Academic Press.

Nash, David George. 1980. Topics in Warlpiri grammar. Cambridge, MA: MIT dissertation. Nespor, Marina \& Wendy Sandler. 1999. Prosody in Israeli Sign Language. Language and Speech 42(2-3). 143-176.

Oomen, Marloes \& Roland Pfau. 2017. Signing NOT (or not): A typological perspective on standard negation in Sign Language of the Netherlands. Linguistic Typology 21(1). 1-51.

Ortmann, Albert. 2000. Where plural refuses to agree: Feature unification and morphological economy. Acta Linguistica Hungarica 47(1-4). 249-288.

Pfau, Roland. 2016. Morphology. In Anne Baker, Beppie van den Bogaerde, Roland Pfau \& Trude Schermer (eds.), The linguistics of sign languages: An introduction, 197-228. Amsterdam: John Benjamins.

Pfau, Roland \& Josep Quer. 2010. Nonmanuals: Their prosodic and grammatical roles. In Diane Brentari (ed.), Sign languages: A Cambridge survey, 381-402. Cambridge: Cambridge University Press.

Pfau, Roland \& Markus Steinbach. 2005. Plural formation in German Sign Language: Constraints and strategies. In Helen Leuninger \& Daniela Happ (eds.), Gebärdensprachen: Struktur, Erwerb, Verwendung (Linguistische Berichte - Sonderhefte 15), 111-144. Hamburg: Buske.

Pfau, Roland \& Markus Steinbach. 2006. Pluralization in sign and in speech: A cross-modal typological study. Linguistic Typology 10. 135-182.

Pizzuto, Elena \& Serena Corazza. 1996. Noun morphology in Italian Sign Language. Lingua 98(13). 169-196.

Power, Justin M., Guido W. Grimm \& Johann-Mattis List. 2020. Evolutionary dynamics in the dispersal of sign languages. Royal Society Open Science 7(1). 191100.

Quer, Josep, Carlo Cecchetto, Caterina Donati, Carlo Geraci, Meltem Kelepir, Roland Pfau \& Markus Steinbach (eds.). 2017. SignGram blueprint: A guide to sign language grammar writing. Berlin: De Gruyter Mouton. https://library.oapen.org/handle/20.500.12657/27399 (accessed 1 October 2019).

R Development Core Team. 2008. R: A language and environment for statistical computing. Vienna: R Foundation for Statistical Computing. http://www.R-project.org.

Sandler, Wendy. 1989. Phonological representation of the sign: Linearity and nonlinearity in ASL. Dordrecht: Foris.

Sandler, Wendy. 1999. Cliticization and prosodic words in a sign language. In Tracy A. Hall \& Ursula Kleinhenz (eds.), Studies on the phonological word, 223-254. Amsterdam: John Benjamins.

Schermer, Trude. 2004. Lexical variation in Sign Language of the Netherlands. https://www. gebarencentrum.nl/media/33555/92_file1.pdf (accessed 23 September 2019).

Steinbach, Markus. 2012. Plurality. In Roland Pfau, Markus Steinbach \& Bencie Woll (eds.), Sign language: An international handbook (HSK - Handbooks of Linguistics and Communication Science 37), 112-136. Berlin: De Gruyter Mouton.

Stokoe, William C. 1960. Sign language structure. Silver Spring, MD: Linstok Press.

Sutton-Spence, Rachel \& Bencie Woll. 1999. The linguistics of British Sign Language: An introduction. Cambridge: Cambridge University Press.

Wilbur, Ronnie. 1987. American Sign Language: Linguistic and applied dimensions. Boston, MA: Little, Brown \& Co. 
Zeshan, Ulrike. 2000. Sign language in Indo-Pakistan: A description of a signed language. Amsterdam: John Benjamins.

Zwitserlood, Inge \& Sibylla Nijhof. 1999. Pluralization in Sign Language of the Netherlands (NGT). In Jan Don \& Ted Sanders (eds.), OTS yearbook 1998-1999, 58-78. Utrecht: UiL OTS. 